\title{
SELEÇÃO E CARREGAMENTO DE MÁQUINAS
}

\author{
Carlos Antônio de Medeiros
}

Orientador: Prof. Dr. José Francisco Ferreira Ribeiro

Dissertação apresentada ao Instituto de Ciências Matemáticas de São Carlos, da Universidade de São Paulo, como parte dos requisitos para obtenção do título de Mestre em Ciências - "Ciência de Computação e Matemática Computacional”.

São Carlos - SP Abril de 1996 
"Deus não joga dados" Albert Einstein 
A meus pais Antonio e Aparecida, minha esposa Vívian e meus irmãos Andréa e Adriano. 


\section{Agradecimentos}

Ao Professor Dr. José Francisco Ferreira Ribeiro pela amizade, orientação, dedicação, estímulo e compreensão.

Ao CNPq pelo apoio financeiro.

Aos colegas Célia, Esdras, Renato, Ricardo e Maristela pela motivação, apoio nos momentos difíceis e pela troca de conhecimento.

E a Deus pelo dom da vida. 


\title{
Seleção e Carregamento de Máquinas
}

\author{
Carlos Antônio de Medeiros
}

Orientador: Prof. Dr. José Francisco Ferreira Ribeiro

\section{RESUMO}

Nesta dissertação é apresentado um método composto de duas fases para efetuar a seleção de máquinas e o carregamento dos produtos sobre as máquinas selecionadas. Na primeira fase é identificado um conjunto de soluções factíveis de um problema da mochila através de programação dinâmica ou de um procedimento heurístico. Na segunda fase, resolve-se um problema de atribuição usando o algoritmo de enumeração implícita ou o algoritmo guloso. $\mathrm{O}$ método proposto foi implementado em linguagem Turbo-Pascal 7.0. 


\title{
Selection and Assignment of Machines
}

Carlos Antônio de Medeiros

Adviser: Prof. Dr. José Francisco Ferreira Ribeiro

\begin{abstract}
In this thesis a two phase method is presented for selection of machines to be kept on the shop floor and assignment of parts to be manufactured to these machines. In the first phase a set of feasible solutions to a knapsack problem is identified by dynamic programming or a heuristic procedure. In the second phase an assignment problem is solved by implicit enumeration technique or a greedy algorithm. The proposed method is written in Turbo-Pascal 7.0.
\end{abstract}




\section{SUMÁRIO}

ÍNDICE DE TABELAS E FIGURAS

i

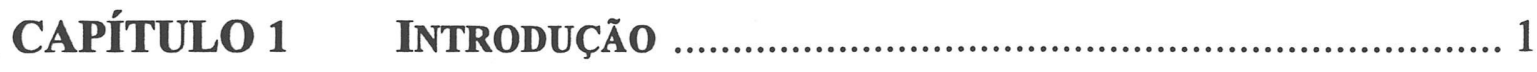

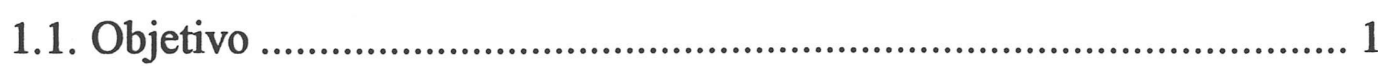

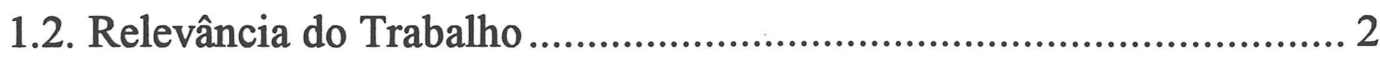

1.3. Organização do Trabalho................................................................. 3

CAPÍTULO 2 Métodos de ReSOLUÇÃo …....................................... 5

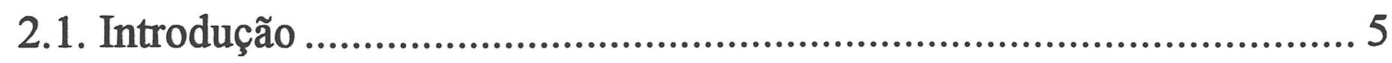

2.2. Complexidade de Algoritmo .......................................................... 10

2.3. Classificação de um algoritmo ............................................................... 11

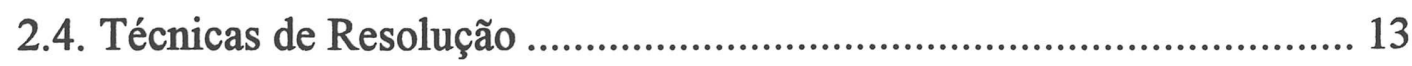

2.4.1. Separação e Avaliação (Branch and Bound) ............................. 13

2.4.1.1. Introdução..................................................................... 13

2.4.1.2. Descrição geral do procedimento .................................... 14

2.4.1.3. Esquema dos Algoritmos por Separação e Avaliação ...... 18

2.4.1.4. Validade dos Algoritmos por Separação e Avaliação....... 18

2.4.1.5. Estratégias Possíveis para o Procedimento Escolha......... 19 
2.4.2. Enumeração Implícita............................................................ 21

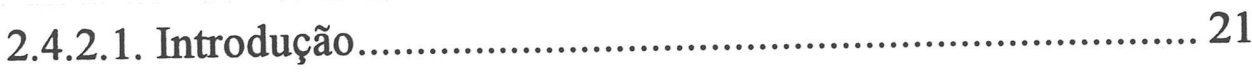

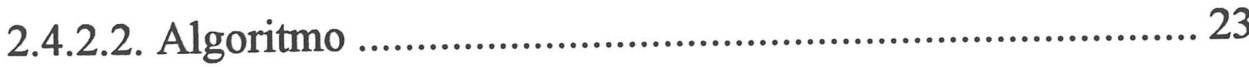

2.4.2.3. Os Passos do Algoritmo ...................................................... 24

2.4.3. Plano de Cortes .................................................................... 26

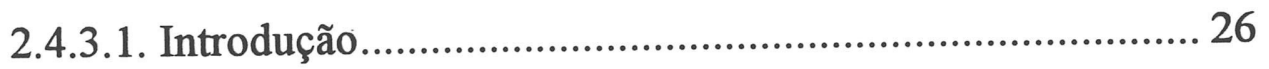

2.4.3.2. Algoritmo de Cortes....................................................... 27

2.4.3.3. Corte de Gomory ............................................................ 27

2.4.3.4. Corte de Dantzig ............................................................... 29

2.4.4. Programação Dinâmica ............................................................ 30

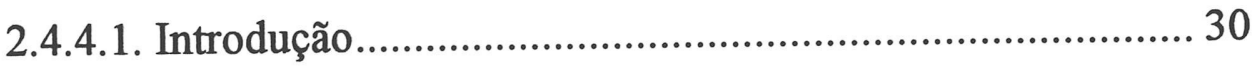

2.4.4.2. O Modelo......................................................................... 31

2.4.4.3. Princípio da otimalidade .................................................. 36

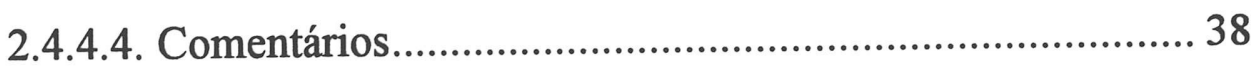

2.4.4.5. Os Problemas de Grande Porte.......................................... 40

2.4.4.6. Avaliação da Técnica......................................................... 44

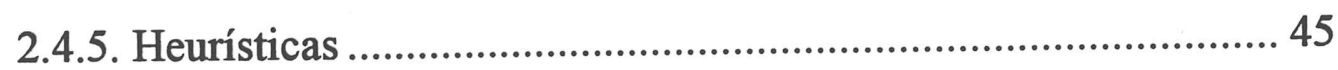

2.4.5.1. Heurísticas Gulosas............................................................. 46

2.4.5.2. Aproximação Local......................................................... 47

2.4.5.3. Esquemas de Aproximação .............................................. 47 


\section{CAPÍTUlo 3 SELEÇão E CARREgamento de Máquinas:}

3.1. Introdução 52

3.2. Notação 54

3.3 Determinação da matriz de cargas ....................................................... 55

3.4 Formulação do Problema ...................................................................... 56

3.5 Decomposição do Problema ................................................................... 57

3.51. Escolha das Máquinas ............................................................ 58

3.52. Atribuição dos lotes de produtos às máquinas ........................... 60

\section{CAPÍTULO 4 IMPLEMENTAÇÃo DO ALGORITMO}

Proposto e Testes Realizados

62

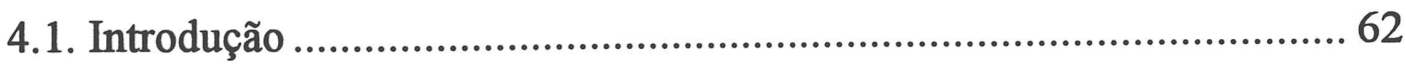

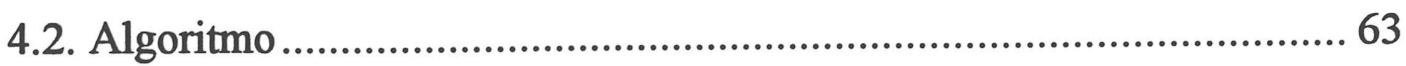

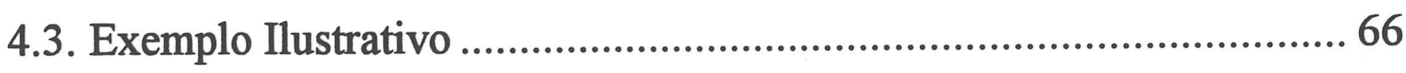

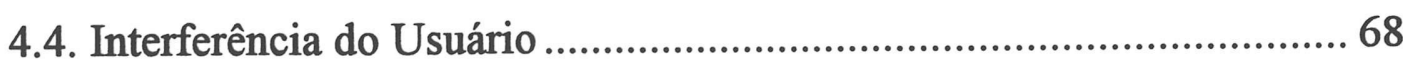

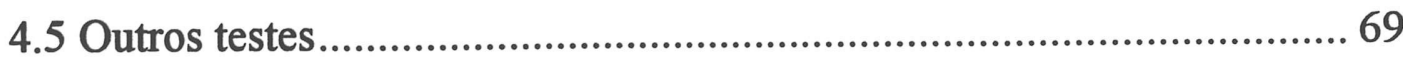

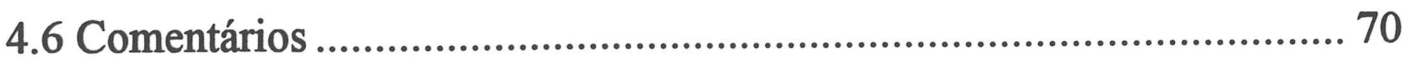

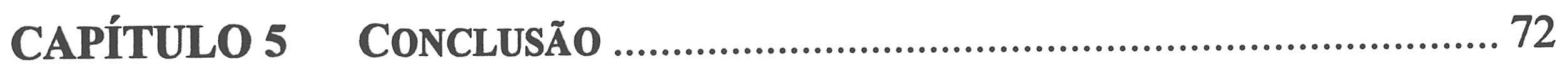

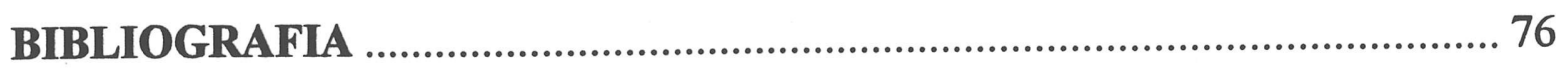




\section{ÍNDICE DE FIGURAS E TABELAS}

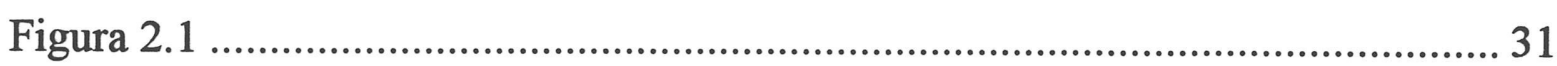

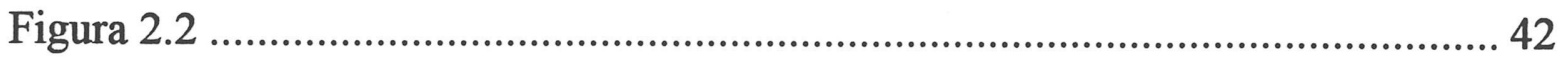

Tabela 2.1

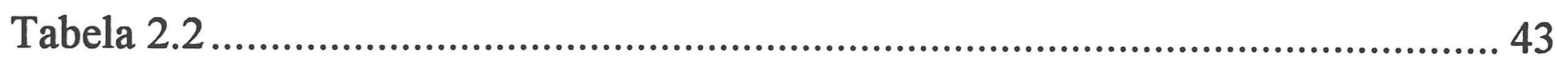

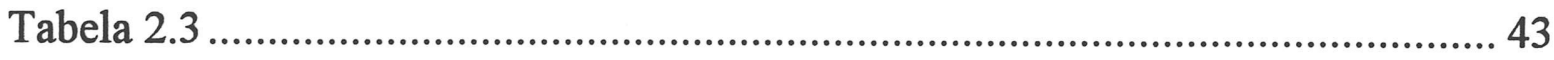

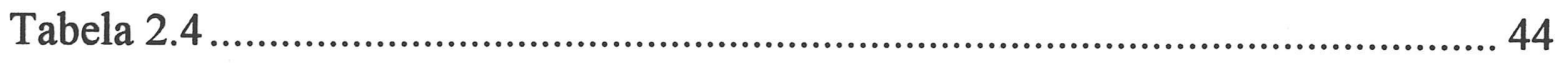

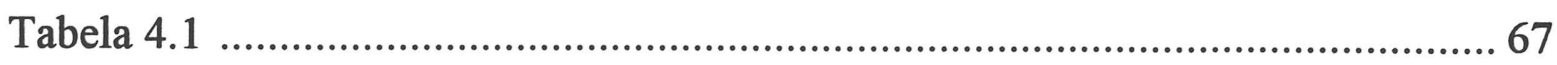

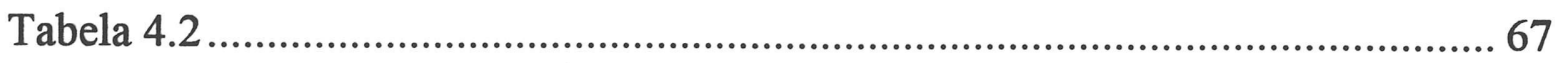

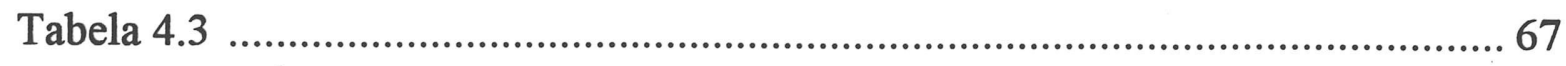

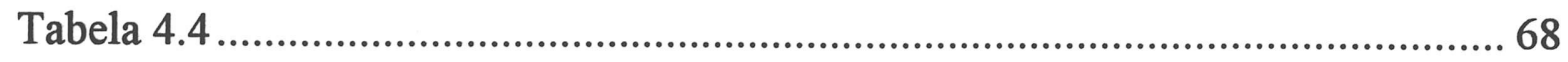

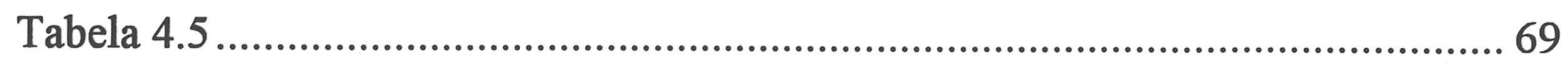

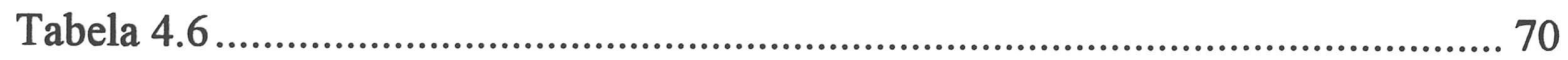




\section{CAPÍTULO 1}

\section{INTRODUÇÃo}

\subsection{Objetivo}

O objetivo deste trabalho consiste em desenvolver e implementar um método e um programa computacional para efetuar (I) a seleção das máquinas responsáveis pela fabricação dos lotes de produtos (ou peças ou lotes de peças) em um sistema de produção e (II) o carregamento das operações a executar sobre estes lotes nas máquinas escolhidas.

Dados os lotes de produtos a fabricar, os roteiros de fabricação de cada lote (ou seja, as sequências ordenadas de operações a executar sobre os produtos), o parque de máquinas-ferramenta disponíveis e as durações das operações, trata-se de:

1) Escolher as máquinas para executar as operações sobre os lotes de produtos entre aquelas do parque de máquinas disponível para elaboração do planejamento;

2) Atribuir os lotes de produtos a fabricar às máquinas escolhidas, respeitandose a capacidade de fabricação das mesmas.

Tais problemas são combinatórios, np-completos (Garey e Johnson, 1979) e tratá-los via algoritmos desenvolvidos pela área de Programação Inteira (tais como : 
separação e avaliação, enumeração implícita, cortes de Gomory ou Dantzig, programação dinâmica, teoria dos grafos, etc.) associados ou não a heurísticas, podem permitir a resolução de exemplos de grande porte em um tempo de cálculo razoável.

\subsection{Relevância do Trabalho}

Em países industrializados como o Brasil, $75 \%$ da produção mecânica é realizada sob a forma de lotes pequenos e médios, com a cadência de fabricação variando de 1 a 50 peças por lançamento (Ferreira Ribeiro, 1991). Neste tipo de produção, a ordem de utilização dos centros de trabalho pelos lotes de produtos é variável e o número de produtos diferentes ou de variantes de um mesmo produto fabricados é considerável. Trata-se da produção do tipo descontínuo ("job shop"), assim denominada por oposição à produção de tipo contínuo ("flow shop"), destinada à fabricação em massa de produtos "standards".

Em uma produção do tipo contínuo, os produtos, as máquinas, a mão de obra, etc., podem ser total ou parcialmente colocados em linha de produção, o que não é possível no caso da produção descontínua. O método Kanban (Schonberger, 1982), implementado pela Toyota Motor Co., é reconhecido como uma ferramenta eficaz e bem adaptada à gestão da produção de tipo contínuo.

Numerosos estudos e contribuições foram realizados na área da fabricação de lotes pequenos e médios (produção descontínua) nos últimos anos. De um lado, o desenvolvimento de células flexíveis de manufaturas, robôs e mecanismos automatizados em geral, e de outro lado, a proposição de novos procedimentos de gestão, como a Tecnologia de Grupo (Burbidge, 1975) e a Gestão da Produção Auxiliada por Computador (GPAO). Em países como a França, 700 dos 1200 GPAO implantados no país (Ferreira Ribeiro, 1991) utilizam o método MRP (Orlicky, 1965) "MRP I : Material Requirements Planning" e "MRP II : Manufacturing Ressource Planning" - para estabelecer um plano diretor de produção e um sequenciamento da produção "ao mais tarde". 
O trabalho realizado nesta dissertação enquadra-se em uma metodologia mais ampla (Ferreira Ribeiro, 1991), concebida para o tratamento específico de três importantes problemas relativos aos sistemas de manufatura. Esta metodologia é composta do processamento sequencial das seguintes fases:

fase 1: seleção e carregamento de máquinas;

fase 2: projeto de células de manufatura;

fase 3: sequenciamento de operações.

Nesta dissertação, é realizado um estudo relacionado à fase 1 da referida metodologia.

A seleção das máquinas que vão realizar efetivamente as tarefas de produção, assim como a atribuição das operações a executar sobre os lotes de produtos a fabricar às máquinas de uma combinação escolhida, constituem tarefas que se revestem de grande importância dentro do contexto da produção descontínua. Estas decisões precedem o projeto de células de manufatura (Ferreira Ribeiro e Pradin, 1993, Ferreira Ribeiro et al., 1993, Ferreira Ribeiro e Ribeiro, 1993, Barbosa e Ferreira Ribeiro, 1995) e o estabelecimento de uma ordem e de um calendário de fabricação (Ferreira Ribeiro e Pradin, 1991a, Noronha e Ferreira Ribeiro, 1994, Oliveira et al., 1994) e têm influência direta sobre o tempo total de fabricação, o aproveitamento dos recursos disponíveis, os níveis de estoque, o respeito ao prazo de entrega, a existência de tempos não produtivos de fabricação ou "tempos mortos", etc.

\subsection{Organização do Trabalho}

Esta dissertação está dividida em cinco capítulos.

No capítulo 2 é apresentado um estudo dos principais métodos disponíveis na área de Programação Inteira para a resolução de problemas combinatórios. Os métodos pesquisados foram os seguintes : Separação e Avaliação ("branch and bound"), Enumeração Implícita (ou especialização "branch and bound" para a resolução de 
problemas em variáveis bivalentes 0/1), Técnica dos Planos de Corte de Gomory e Dantzig, Programação Dinâmica e Heurísticas (ou algoritmos aproximados). Os textos pesquisados para a redação deste capítulo foram os seguintes: Larson (1968), Arduino (1972), Salkin (1975) Papadimitriou e Steiglitz (1982), Minoux (1983), Sakarovitch (1984), Gondran e Minoux (1985), Bronson (1985) e Wagner (1986).

O capítulo 3 é destinado à apresentação do problema específico tratado nesta dissertação. A notação utilizada é introduzida, assim como o procedimento para o cálculo da matriz de cargas de trabalho. Uma formulação matemática do problema global de seleção e carregamento de máquinas é proposta e dado o caráter np-completo dos mesmos, é definida uma estratégia de decomposição em duas fases para a resolução do problema. Outras abordagens descritas na literatura para a resolução deste problema são igualmente discutidas e comentadas.

A implementação computacional do método de resolução proposto, assim como os testes computacionais realizados são apresentados no capítulo 4. Para a resolução do problema de seleção das máquinas codificou-se um algoritmo, cujo resultado é o conjunto das soluções factíveis do problema, quando a enumeração é processada via Programação Dinâmica (Larson, 1968), ou um conjunto soluções factíveis de cardinal inferior ou igual a 10, quando processa-se uma busca de soluções factíveis para problemas de grande porte, ou seja, com mais de 100 variáveis $0 / 1$ a determinar. $\mathrm{O}$ problema de carregamento das máquinas é igualmente resolvido através de duas técnicas: Se o número de variáveis do problema tratado não exceder dois dígitos, resolve-se o problema através do algoritmo de enumeração implícita (Sakarovitch, 1984), caso contrário, aplica-se o algoritmo guloso (Aho et al., 1983). O programa computacional foi escrito em Turbo Pascal 7.0.

As observações finais e as propostas de continuidade para este trabalho são apresentadas na Conclusão. 


\section{CAPÍTULO 2}

\section{Problemas de ProgramaÇão Inteira e}

\section{MÉTOdOS DE RESOLUÇÃo}

\subsection{Introdução}

Os problemas a serem tratados nesta dissertação (seleção e carregamento de máquinas) enquadram-se na classe dos problemas discretos, combinatórios ou inteiros, de grande complexidade e difícil resolução, dado o grande número de alternativas de soluções que devem ser exploradas com o objetivo de determinar-se a solução ótima ou uma solução factível de boa qualidade.

Nestes problemas de otimização combinatória, exige-se que o resultado se apresente na forma de valores inteiros. Tipicamente, trata-se dos problemas onde as variáveis a determinar representam objetos indivisíveis, como, por exemplo : homens, máquinas, etc. Os programas matemáticos associados a estes problemas são chamados de programas matemáticos em números inteiros (PMI). 
A enumeração completa de todas as soluções viáveis de um problema de otimização discreta limitado conduz à solução ótima em número finito de passos. Infelizmente, pode-se mostrar que, mesmo para problemas de porte pouco significativo, o número de passos será tão grande que o computador mais avançado levaria séculos no processo de cálculo. Em um problema, por exemplo, cujo número de soluções viáveis seja $n$ ! e considerando que cada uma delas será examinada em $10^{-9}$ segundos tem-se:

\begin{tabular}{|c|c|}
\hline $\mathrm{n}$ & tempo execução \\
\hline 20 & 800 anos \\
\hline 21 & 16.800 anos \\
\hline
\end{tabular}

Tabela 2.1 - Enumeração Completa.

A variação observada é, muitas vezes, chamada na literatura de "explosão exponencial". Este resultado não é surpreendente, uma vez que o algoritmo de enumeração completa é o mais primitivo algoritmo de busca.

Seja A uma matriz $\mathrm{m} \times \mathrm{n}$; c um $\mathrm{n}$-vetor linha e b um $\mathrm{m}$-vetor coluna. $\mathrm{O}$ programa matemático abaixo é um PMI linear.

$\begin{array}{cll}\text { Otimize } & \mathrm{Z}=\mathrm{cx} & 2.1 \\ \text { s/a } & \mathrm{Ax} \leq \mathrm{b} & 2.2 \\ & \mathrm{x} \geq 0 & 2.3 \\ & \mathrm{x}_{\mathrm{j}} \text { inteiro } & 2.4\end{array}$

Dependendo do sentido de otimização, a função objetivo 2.1 pode ser maximização ou minimização. As estipulações de valores discretos 2.4 é que distinguem um problema de Programação Inteira de um de Programação Linear. Em geral, impor 2.4 é restritivo, de modo que o valor máximo (mínimo) de uma função 
objetivo para o problema de Programação Inteira é comumente menor (maior) que para o problema linear correspondente.

Existem várias circunstâncias de ocorrência freqüente que levam a modelos de planejamento contendo variáveis de valores inteiros. Entre estes, podemos citar:

A) Utilização de equipamentos - pode-se definir uma variável $\mathrm{x}_{\mathrm{j}}$ como as unidades de equipamentos que devem operar durante o horizonte de planejamento do modelo. Se cada unidade de equipamento fornecer uma grande capacidade e tiver um alto custo, por exemplo, uma máquina automática de fazer parafusos ou um navio petroleiro, então um valor fracionário para $x_{j}$ pode não ter significado (não ser realizável) no contexto da decisão real. Neste caso, restringe-se $x_{j}$ a um valor inteiro.

B) Tamanho de lotes - Em algumas situações pode-se querer restringir o nível de $x_{j}$ a $x_{j}=0$ ou $x_{j} \geq L_{j}$, onde $x_{j}$ pode ser a quantidade de um produto a ser fabricado e $L_{j}$ representa o tamanho mínimo possível de lote de produção para o item. Esta estipulação pode ser formulada introduzindo variáveis inteiras.

C) Custo de preparação - A consideração de uma atividade que esteja sujeita a um chamado custo fixo (ou custo de preparação) $C_{j}$ sempre que o nível correspondente $x_{j}>0$, onde $C_{j}$ é independente do nível real de $x_{j}$. Pode-se introduzir variáveis inteiras para englobar os custos de preparação em um modelo de programação linear.

D) Decisões "Sim-ou-Não" - A especificação de tipos de situações "ou-ou". Para fazer isto, pode-se restringir $x_{j}=1$ ou $x_{j}=0$, representando as decisões "sim" ou "não". Pode-se fazer $x_{j}=1$ corresponder a construir uma nova fábrica, adquirir um outro negócio, vender um bem possuído no presente, ou $x_{j}=0$ caso contrário. Neste caso, enquadra-se o problema da escolha de máquinas a utilizar. Quando tem-se em 
(2.2) um vetor linha A (ou seja, apenas uma restrição) tal problema é denominado na literatura de "Problema da Mochila".

E) Problema da mochila - Um problema de alocação de recursos que tenha uma função objetivo linear e uma única restrição linear representa uma classe importante de aplicações. Historicamente, este problema surgiu da seguinte forma: Um alpinista deve escolher objetos para levar em sua mochila, selecionando entre vários objetos aqueles que lhe darão um máximo conforto. Este "problema da mochila" pode ser formulado numerando-se os objetos de $1 \mathrm{a} n$ e introduzindo um vetor de variáveis binarias $\mathrm{x}_{\mathrm{j}}(\mathrm{j}=$ $1,2, \ldots, \mathrm{n})$ onde:

$$
\mathrm{x}_{\mathrm{j}}= \begin{cases}1 & \text { se objeto } \mathrm{j} \text { é selecionado } \\ 0 & \text { caso contrario }\end{cases}
$$

Então, se $\mathrm{p}_{\mathrm{j}}$ é uma medida de conforto dada ao objeto $\mathrm{j}, \mathrm{w}_{\mathrm{j}}$ o seu "tamanho" e c o "tamanho da mochila", o problema consiste em selecionar uma solução satisfazendo a restrição.

$$
\sum_{j=1}^{n} w_{j} x_{j} \leq c
$$

e que maximize a função objetivo:

$$
\sum_{j=1}^{n} p_{j} x_{j}
$$

F) Problema da Mochila Multidimensional - Uma grande variedade de problemas do tipo "atribuição" pode aparecer sob a forma de um programa linear inteiro, dos quais os problemas de partição e recobrimento são casos particulares. Seja o problema de otimização: 


$$
\begin{aligned}
& (\max ) \mathrm{z}=\mathrm{c} x \\
& \text { s/a } \quad \mathrm{Ax}=\mathrm{b} \\
& \quad \mathrm{xj}=0 / 1, \quad \mathrm{j}=1 \ldots \mathrm{n}
\end{aligned}
$$

onde A é uma matriz $\mathrm{m} \times \mathrm{n}$ com coeficientes inteiros não negativos, $\mathrm{b}$ é um $\mathrm{m}$-vetor de inteiros positivos e c um n-vetor de inteiros não negativos. Se $\mathrm{m}=1$, ou seja, no caso em que se tem uma única restrição, o problema é conhecido como o problema da mochila. No problema da mochila multidimensional são impostas restrições suplementares sobre o comprimento, o volume, etc. Neste contexto, o problema da mochila surge naturalmente nos casos de carregamento de máquinas, navios, aviões ou caminhões; nos problemas de cortes industriais ou de escolha de investimentos; assim como nos casos particulares de recobrimento e "matching" em hipergrafos (Gondran e Minoux, 1985).

Em princípio, os problemas de Programação Inteira deveriam ser mais fáceis de resolver que os problemas de Programação Linear de mesma dimensão. Para sustentar esta opinião, basta observar-se que uma dicotomia do tipo $x_{j}=0$ ou $x_{j}=1$, contém um número consideravelmente menor de alternativas de solução do que contém o conjunto contínuo $0 \leq \mathrm{x}_{\mathrm{j}} \leq 1$. A busca do ótimo, então, deveria ser mais simples. Entretanto, para problemas de grande porte, acontece exatamente o contrário: a computação é mais fácil sobre um conjunto contínuo do que sobre alternativas discretas.

Uma primeira abordagem para encontrar uma solução de valor inteiro consiste em ignorar a restrição de integralidade e determinar a solução ótima via Programação Linear. Se esta resposta satisfaz a restrição de integralidade, então a solução ótima para o problema original foi encontrada. Caso contrário, pode-se obter uma solução inteira arredondando a resposta obtida da Programação Linear. Nem sempre esta solução é viável, ou então é viável porém distante da solução ótima. Daí, embora o arredondamento possa ter êxito em algumas aplicações, não se pode esperar que esta abordagem seja recomendável. 
Uma dificuldade ainda mais séria inerente a problemas de Programação Inteira é que não há maneira fácil de verificar se uma solução viável dada é realmente ótima. Poderia surgir a idéia de enumerar-se todas as soluções viáveis e, então tomar-se como solução a melhor. Se houver poucas soluções possíveis, tal procedimento exaustivo pode ser bem mais fácil de implementar do que qualquer dos algoritmos apresentados mais adiante no capítulo. Em algumas aplicações reais, esta tem sido a abordagem utilizada (freqüentemente, um número de soluções possíveis é abandonado imediatamente como "obviamente" não-ótimas). Mais freqüentemente, contudo, uma abordagem exaustiva prova-se impraticável, e a razão, simplesmente, é que o número de soluções viáveis não é sempre finito e, mesmo quando o seja, a magnitude é comumente enorme. Por exemplo, determinar-se a solução ótima de um problema de Programação Inteira que com 500 variáveis, cada uma restrita a ser 0 ou 1 . O tempo exigido para enumerar todas as $2^{500}$ possibilidades mesmo no computador mais rápido disponível é da ordem de séculos, o que invalida a utilização deste procedimento para problemas desta dimensão.

\subsection{Complexidade de Algoritmo}

A garantia da existência de uma solução ou mesmo o fato de determinado algoritmo ser convergente ou não, diz muito pouco sobre sua aplicabilidade na resolução de um problema de otimização combinatória. É necessário distinguir entre um "bom" ou "mau" algoritmo. Esta necessidade deu origem à "Teoria da Complexidade" (Aho et al., 1983, Szwarcfiter, 1983, Campelo e Maculan, 1994) amplamente utilizada no campo da Otimização Discreta.

A complexidade de um algoritmo avalia o número de instruções executadas por este algoritmo com relação ao comprimento da codificação dos dados utilizados. Ela é descrita pela notação "O". Seja f uma função real não negativa de uma variável inteira $n \geq 0$. Diz-se que $f$ é $O(h)$ se existem constantes $c, n_{0}>0$ tais que $f(n) \leq c * h$, para $n \geq n_{0}$. 
Normalmente o cálculo da complexidade de um algoritmo é realizado para o pior caso: Esta complexidade traduz um limite superior do número de instruções executadas pelo algoritmo para um conjunto de dados suficientemente grande.

Como exemplo, seja o algoritmo abaixo:

Algoritmo ordenação de números

$$
\begin{aligned}
& \mathrm{S}=\left\{\mathrm{s}_{1}, \ldots, \mathrm{s}_{\mathrm{n}}\right\} \\
& \text { enquanto existir inversões } \mathrm{s}_{\mathrm{i}} \text { e } \mathrm{s}_{\mathrm{j}} \text { fazer } \\
& \quad \text { trocar de posição } \mathrm{s}_{\mathrm{i}} \text { e } \mathrm{s}_{\mathrm{j}}
\end{aligned}
$$

fim enquanto

\section{fim Algoritmo}

Seja q o número de inversões de uma seqüência $\mathrm{S}$. Seja $\mathrm{n}$ o comprimento da codificação dos dados. A identificação das inversões de $S$ pode ser realizada em $O(n q)$. $\mathrm{O}$ número máximo de inversões q corresponde ao caso onde $\mathrm{S}$ é fornecida em ordem decrescente: $q_{\max }=n(n-1) / 2$. O número mínimo de inversões $q$ corresponde ao caso onde $S$ é fornecida já ordenada: $q_{\min }=0$. A leitura dos dados é realizada em $O(n)$. Assim, as complexidades do melhor e do pior caso são respectivamente iguais a O(n) e $\mathrm{O}\left(\mathrm{n}^{3}\right)$. Diz-se que o algoritmo ordenação de números acima é $\mathrm{O}\left(\mathrm{n}^{3}\right)$.

\subsection{Classificação de um algoritmo}

Um problema algoritmo pode se apresentar sob a forma de um problema de existência, de localização, de otimização, etc.

Um problema de existência pertence à classe $\mathrm{P}$ ( $\mathrm{P}$ como polinômio) se existir um algoritmo polinomial ou "eficaz" para resolvê-lo. Chamamos de polinomial um 
algoritmo cuja complexidade é uma função polinomial do comprimento da codificação dos dados do problema. Para um comprimento igual a $\mathrm{n}$, consideramos polinomiais os algoritmos cuja complexidade são $\mathrm{O}(1), \mathrm{O}(\mathrm{n}), \mathrm{O}\left(\mathrm{n}^{10}\right)$ ou $\mathrm{O}(\mathrm{n} \operatorname{logn})$. Os algoritmos de complexidade $\mathrm{O}\left(2^{\mathrm{n}}\right)$ ou $\mathrm{O}(\mathrm{n}$ !) são considerados "ineficientes" e são chamados de algoritmos exponenciais. Evidentemente, para um comprimento $n=2$, um algoritmo $\mathrm{O}\left(2^{\mathrm{n}}\right)$ é mais "eficiente" que um algoritmo $\mathrm{O}\left(\mathrm{n}^{10}\right)$ uma vez que $2^{2}=4$ é menor que $2^{10}=1024$. Mas para $n$ suficientemente grande, o algoritmo $\mathrm{O}\left(2^{\mathrm{n}}\right)$ é "menos eficiente" que um algoritmo $\mathrm{O}\left(\mathrm{n}^{10}\right)$ e assim $\mathrm{O}\left(\mathrm{n}^{10}\right)$ é, entre os dois, aquele que consideramos "eficiente".

Um problema de existência pertence a classe NP (comportamento polinomial não-determinado) se existir um algoritmo polinomial ou "eficiente" de tipo nãodeterminista para resolvê-lo. Um algoritmo de tipo não-determinista é um algoritmo teórico dotado de uma instrução imaginária denominada ESCOLHA (Sakarovitch, 1984) capaz de tomar imediatamente a boa decisão.

Os algoritmos polinomiais ordinários formam um subconjunto dos algoritmos não-deterministas. Assim NP $\supset \mathrm{P}$ e todos os problemas pertencentes à classe $\mathrm{P}$ constituem também problemas pertencentes à classe NP. Uma conjectura que instiga os especialistas é saber se $\mathrm{P}=\mathrm{NP}$, mas não se pode demonstrá-la positivamente até o momento e muitos a consideram improvável.

Um problema de existência pertence à classe NP-completo se (I) pertencer à classe NP e se (II) for possível transformá-lo em tempo polinomial em um outro problema qualquer da classe NP. Estes problemas são os mais importantes da classe NP pois se pudéssemos resolver um destes problemas com a ajuda de um algoritmo eficiente, então todo problema da classe NP poderia igualmente ser resolvido. Por outro lado, muitos consideram que se um problema é NP-completo, tem-se um algoritmo suficientemente forte para interromper a busca de um algoritmo eficiente para resolvê-lo. Cook (1971) demonstrou pela primeira vez a existência de um problema NP-completo: o problema da cláusula booleana. Depois, problemas tais como o da programação em números inteiros (mochila, partição,...), que pertencem à classe NP foram transformados polinomialmente neste problema, integrando assim a 
classe dos problemas NP-completos. Uma lista bastante extensa de problemas NPcompletos está disponível em Garey-Johnson (1979).

Um problema é "indecidível" se não se dispõe de algoritmo (nem polinomial, nem exponencial, nem não-determinista) para resolvê-lo. Este é o caso do problema de Turing (seja um texto algorítmico a e um conjunto de dados d, determinar se a execução do texto a com os dados d tem fim ou não) para o qual Turing mostrou a inexistência de algoritmo.

\subsection{Técnicas de Resolução}

Neste item são estudadas cinco técnicas para resolução de um Problema de Programação Linear Inteira (P.P.L.I.), a saber: Separação e Avaliação, Enumeração Implícita, Planos de Cortes, Programação Dinâmica e Heurísticas.

\subsection{1 - Separação e Avaliação (Branch and Bound)}

\subsubsection{1 - Introdução}

Considera-se o seguinte problema:

Minimizar $\mathrm{z}=\mathrm{f}(\mathrm{x}), \mathrm{f}: \Omega \rightarrow \mathrm{R}$ ( $\Omega$ conjuntos das soluções factíveis) ou seja, determinar $\bar{x} \in \Omega$ tal que $f(\bar{x})=\min \{f(x)\}$ para $x \in \Omega$.

É sempre possível resolver este problema enumerando-se todas as soluções de $\Omega$. Para se efetuar esta enumeração de maneira sistemática, tem-se interesse, em geral, 
em se decompor de maneira progressiva o conjunto de soluções $\Omega$. Esta decomposição é chamada de "arborescente" pois é cômodo associar uma arborescência a este tipo de procedimento: o conjunto $\Omega$ corresponde à raiz da arborescência associada. Uma etapa da decomposição consiste em escolher um subconjunto $\Omega^{\prime}$ de $\Omega$ que corresponde a um nó pendente da arborescência e a separá-lo (quer dizer: particionálo, em geral) em subconjuntos $\Omega_{1}^{\prime}, \Omega_{2}^{\prime}, \ldots, \Omega_{\mathrm{k}}^{\prime}$. O nó da arborescência correspondente a $\Omega$ ' é então unido através de arcos aos nós criados correspondentes aos subconjuntos de $\Omega$ '. A eficiência desta exploração arborescente pode ser aumentada se tem-se disponível um meio para evitar o exame de todas as partes nas quais o conjunto de soluções é decomposto. Nos procedimentos por separação e avaliação é uma função de avaliação que permite a eliminação de ramos inteiros da arborescência e de localizar uma solução ótima.

\subsubsection{2 - Descrição geral do procedimento}

Os procedimentos de separação e avaliação constituem uma área mais ampla no interior da qual diferentes algoritmos são especificados quando são estabelecidos:

a)como definir os subconjuntos nos quais o conjunto $\Omega$ é progressivamente decomposto,

b)como realizar a escolha do subconjunto a tratar, ou seja, como efetuar a avaliação e a separação.

O primeiro procedimento consiste em decidir como serão caracterizados os subconjuntos gerados. Esta decomposição é freqüentemente ditada pela estrutura de $\Omega$. 
Definicão-1 : Dado um problema de otimização combinatória (P), diz-se que sabe-se "avaliar" o subconjunto $\Omega$ ' de $\Omega$ se sabe-se determinar um real $g(\Omega$ ') tal que:

$$
g\left(\Omega^{\prime}\right) \leq f(x) \text { para todo } x \in \Omega^{\prime}
$$

Se $\Omega^{\prime}=\varnothing$, a única avaliação possível é $g\left(\Omega^{\prime}\right)=+\infty$. Uma avaliação $g\left(\Omega^{\prime}\right)$ é dita "exata" se é conhecido $\overline{\mathrm{x}}\left(\Omega^{\prime}\right) \in \Omega^{\prime}$ tal que $g\left(\Omega^{\prime}\right)=f\left(\overline{\mathrm{x}}\left(\Omega^{\prime}\right)\right)$. Uma avaliação $g^{\prime}(\Omega$ ') é dita "melhor" que a avaliação $g(\Omega$ ') se

$$
g^{\prime}\left(\Omega^{\prime}\right)>g\left(\Omega^{\prime}\right)
$$

Obs. 1.: Se o problema de otimização combinatória considerado é um problema de maximização (procura-se um elemento $\bar{x}$ tal que $f(\bar{x})=\max \{f(x)\}$ para $x \in \Omega$ ), as definições de avaliação e de uma melhor avaliação acima continuam válidas, invertendo-se as inequações em 2.5 e 2.6. A definição de uma avaliação exata se transpõe de maneira direta.

Obs.2: Se $\mathrm{g}\left(\Omega^{\prime}\right)$ é uma avaliação exata, não pode existir avaliação de melhor qualidade.

Definicão-2 : Um subconjunto $\Omega$ ' do conjunto $\Omega$ das soluções de um problema de otimização combinatória é dito "esterilizado" em um dos seguintes casos:

a) $\Omega^{\prime}=\varnothing$

b) conhece-se uma solução $\overline{\mathrm{x}} \in \Omega$ ao menos tão boa quanto todas as outras soluções de $\Omega$ '. Ou seja:

$$
\begin{aligned}
& f(\overline{\mathrm{x}}) \leq g\left(\Omega^{\prime}\right) \\
& f(\overline{\mathrm{x}}) \geq g\left(\Omega^{\prime}\right) \text { para um problema de maximização. }
\end{aligned}
$$


Um subconjunto $\Omega$ ' de $\Omega$ pode ser esterilizado se tem-se certeza que $\Omega^{\prime}$ não pode conter a solução ótima (o que é o caso quando $\Omega^{\prime}=\varnothing$ ou quando a avaliação de $\Omega$ ' é superior ao valor de melhor solução conhecida) ou se dispõe de uma avaliação exata de $\Omega$ '. Em nenhum destes casos há necessidade de prosseguir a decomposição de $\Omega$ ': é justamente esta situação que o conceito de esterilizado caracteriza.

Definição-3: Um subconjunto $\Omega$ ' de $\Omega$ é dito "separado" em subconjuntos $\Omega_{1}^{\prime}, \Omega_{2}^{\prime}, \ldots, \Omega_{\mathrm{k}}^{\prime}$ se:

$$
\begin{aligned}
& \Omega_{\mathrm{i}}^{\prime} \subset \Omega^{\prime} \quad i=1,2, \ldots k \\
& \Omega_{1}^{\prime} \cup \Omega_{2}^{\prime} \cup \ldots \cup \Omega_{\mathrm{k}}^{\prime}=\Omega^{\prime}
\end{aligned}
$$

Não são excluidas as "falsas" separações, ou seja, aquelas para as quais certos conjuntos $\Omega_{\mathrm{i}}^{\prime}$ são vazios. No caso mais freqüente, os conjuntos $\Omega_{\mathrm{i}}^{\prime}$ serão dois a dois disjuntos, mas isto não é necessário.

Teorema-1: Seja $\mathcal{f}$ uma família de subconjuntos de $\Omega$ cuja união é igual $\Omega$. Então:

a) Se $\Omega^{\prime}$ está separado em $\Omega_{1}^{\prime}, \Omega_{2}^{\prime}, \ldots, \Omega_{\mathrm{k}}^{\prime} . \overline{f^{\prime}}=\overline{\mathcal{f}} \cup\left\{\Omega_{1}^{\prime}, \Omega_{2}^{\prime}, \ldots, \Omega_{\mathrm{k}}^{\prime}\right\} \backslash\left\{\Omega^{\prime}\right\}$ é ainda uma família de subconjuntos de $\Omega$ cuja união é igual $\Omega$.

b) Se todos os conjuntos da família $\mathcal{I}$ tem uma avaliação exata, e se $\Omega$ ' é um subconjunto de avaliação mínima, então $\overline{\mathrm{x}}\left(\Omega^{\prime}\right)$ é solução ótima de $(\mathbf{P})$ a menos que $\mathrm{g}\left(\Omega^{\prime}\right)=+\infty(\Omega=\varnothing)$.

Demonstração: conseqüência direta das definições 1,2 e 3 . 
No esquema geral dos métodos de separação e avaliação apresentado no algoritmo abaixo, designa-se por:

$-\bar{x}$ a melhor solução conhecida e $v=f(\bar{x})$. No início $\bar{x}$ é indeterminado e $v=+\infty$ ( $\infty$ para um problema de maximização).

- $\mathcal{L}$ é uma família de subconjuntos de $\Omega$ não esterilizados.

O esquema apresentado é um esboço geral dos algoritmos de separação e avaliação. Um algoritmo particular só será definido quando especificar-se:

a) a escolha do subconjunto a tratar no "procedimento escolha"

b) a avaliação no "procedimento avaliação"

c) a separação no "procedimento separação".

Aliás, as variantes deste esquema são freqüentes. Pode-se por exemplo, proceder uma avaliação grosseira e aproximativa dos conjuntos $\Omega$ ' quando eles são criados e então refinar esta avaliação antes de proceder a separação (que será evitada se $\Omega$ ' é esterilizado). Embora trate-se de um esquema, na medida em que não contém todos os algoritmos, ele fornece a idéia da estrutura do método. Uma outra maneira de caracterizar estes algoritmos consiste em dizer que é preciso que as hipóteses do Teorema 1 se apliquem. 


\subsubsection{Esquema dos Algoritmos por Separação e Avaliação}

início esquema

$\overline{\mathrm{x}}=$ indeterminado;

$\mathrm{v}=+\infty$ (ou $-\infty$ para o problema de maximização);

$\mathcal{f}=\{\Omega\}$

enquanto $\mathcal{f} \neq \varnothing$ fazer

procedimento escolha: escolher um conjunto $\Omega^{\prime} \in \mathcal{f}$ que não tenha sido avaliado se tal $\Omega^{\prime}$ existe, senão escolher um $\Omega^{\prime} \in \mathcal{f}$ avaliado; se $\Omega$ ' não foi avaliado então

procedimento avaliação: associar a $\Omega^{\prime}$ sua avaliação $\mathrm{g}\left(\Omega^{\prime}\right)$; se $\mathrm{g}\left(\Omega^{\prime}\right) \geq \mathrm{v}$ ( $\leq$ para problema de maximização) então

$$
\mathcal{f}=\mathcal{f} /\left\{\Omega^{\prime}\right\}
$$

senão se a avaliação é exata então

$$
\begin{aligned}
& \overline{\mathrm{x}}=\overline{\mathrm{x}}\left(\Omega^{\prime}\right) ; \\
& \mathrm{v}=\mathrm{f}(\overline{\mathrm{x}})=\mathrm{g}\left(\Omega^{\prime}\right) ; \\
& \mathcal{f}=\mathcal{f} /\left\{\Omega^{\prime}\right\} ;
\end{aligned}
$$

fim se

fim se

senão procedimento separação: cria-se os subconjuntos $\Omega_{1}^{\prime}, \Omega_{2}^{\prime}, \ldots, \Omega_{\mathrm{K}}^{\prime}$;

$$
\mathcal{N}^{\prime}=\mathcal{f} \cup\left\{\Omega_{1}^{\prime}, \Omega_{2}^{\prime}, \ldots, \Omega_{\mathrm{K}}^{\prime}\right\} /\left\{\Omega^{\prime}\right\}
$$

fim se

fim enquanto

fim esquema

\subsubsection{4 - Validade dos Algoritmos por Separação e Avaliação}

Para que o algoritmo, seguindo o esquema geral acima esteja correto, é preciso em primeiro lugar que a busca seja possível, ou seja, que todo conjunto $\Omega$ ' criado possa ser avaliado e todo conjunto $\Omega$ ' para o qual a avaliação não seja exata possa ser separado. Se fizermos $\bar{f}=\mathcal{f} \cup\left\{\Omega^{\prime} / \Omega^{\prime}\right.$ tenha sido esterilizado $\}$, então F satisfaz as hipóteses do Teorema 1 , o que demonstra a validade do critério de parada. 
Portanto, é suficiente, para fornecer a justificativa de um algoritmo inscrito no esquema geral acima, demonstrar a sua convergência. Esta convergência não é uma conseqüência direta do fato que $\Omega$ é finito como se poderia crer a primeira vista: a possibilidade que foi deixada em aberto (conforme definição 3) das "falsas separações" proíbem, com efeito, a conclusão para o caso geral. Alguns autores têm estudado as condições mínimas que devem ser satisfeitas para que um algoritmo "geral" seja finito. Esta pesquisa da generalidade máxima tem se revelado bastante estéril. Como conseqüência, a convergência deve ser demonstrada para cada algoritmo específico. Estas demonstrações, entretanto, são triviais para a grande maioria dos casos (Sakarovitch 1994).

É bastante cômodo visualizar a implementação dos métodos de separação e avaliação associando-se uma arborescência à decomposição progressiva do conjunto $\Omega$. Em cada etapa, aos nós pendentes da arborescência associada correspondem os subconjuntos de $\mathcal{f}$. Quando o subconjunto $\Omega$ ' é separado, criam-se novos nós pendentes correspondendo aos subconjuntos $\Omega_{\mathrm{i}}^{\prime}(\mathrm{i}=1,2, \ldots, \mathrm{k})$. Estes nós são evidentemente adjacentes ao nó correspondendo a $\Omega$ '. Esta arborescência está associada de maneira tão natural ao método, que se diz, muitas vezes, tratar um nó ou separar um nó. É preciso, é claro, entender que se trata do subconjunto ao qual este nó está associado. Estas notações para os termos não devem causar confusão.

\subsubsection{5 - Estratégias Possíveis para o Procedimento Escolha}

a) Selecionar o conjunto $\Omega$ ' cuja avaliação seja a menor (respectivamente a maior para o problema de maximização) com a "idéia" de que este subconjunto tenha maiores possibilidades de conter a solução ótima. 
b) Selecionar o conjunto $\Omega$ ' criado mais recentemente (a família $\mathcal{f}$ funciona, então, como uma pilha). Esta maneira de fazer corresponde a uma exploração em profundidade ou por "backtracking" da arborescência criada.

c) Selecionar o conjunto $\Omega^{\prime}$ criado mais anteriormente (a família $\mathcal{f}$ é gerenciada como FIFO: primeiro a entrar, primeiro a sair). Esta maneira de fazer corresponde a uma exploração em largura.

A exploração em largura possui duas vantagens e um inconveniente:

i)A primeira vantagem consiste em obter rapidamente uma solução factível $\bar{x}$, o que é interessante pois existe a necessidade de um valor finito de $\mathrm{v}$ para esterilizar os subconjuntos.

ii)A segunda vantagem consiste em limitar ao mínimo as transferências entre memória central e periférica. Com efeito, para problemas de médio porte, é impossível guardar na memória central todas as informações relativas a cada nó pendente na arborescência. Tratando o último nó criado, pode-se freqüentemente utilizar as informações armazenadas na memória central.

iii) $\mathrm{O}$ inconveniente consiste em não levar-se em consideração a função de avaliação. Ou seja, pode-se ser conduzido a tratar subconjuntos cuja avaliação é medíocre e que tem poucas chances de conter a solução ótima.

$\mathrm{Na}$ prática, utiliza-se uma mistura das estratégias a e b: utiliza-se o backtracking para "descer" na arborescência. Uma vez encontrada uma solução $\bar{x}$, escolhe-se o subconjunto não estéril de avaliação mínima (respectivamente máxima para o problema de maximização). A estratégia de exploração em largura não apresenta as vantagens da exploração em profundidade. Ela é pouco utilizada (Gondran e Minoux, 1985).

Os procedimentos de separação e avaliação podem ser considerados um caso particular de busca arborescente. $\mathrm{O}$ desenvolvimento de algoritmos para a resolução 
de problemas e da inteligência artificial aumentaram a importância destes métodos. A busca arborescente se diferencia dos procedimentos de separação e avaliação tais como foram apresentados porque ela visa tratar uma classe maior de problemas que aqueles pertencentes à otimização combinatória e também porque a exploração da arborescência para se determinar uma solução não é guiada pelo valor da função de avaliação. Um procedimento de busca arborescente é mais precisamente caracterizado pelos seguintes fatores:

a) estado de informação que correspondem aos nós da arborescência,

b) um jogo de regras especificando quais estados de informação podem suceder um estado de informação dado,

c) uma estratégia de controle para gerenciar o comportamento do algoritmo. As regras operam sobre os estados de informação, mas uma não chama a outra. É a estratégia de controle que decide qual regra deve ser aplicada em qual momento.

A distinção entre os três elementos acima é importante. Novas regras podem ser utilizadas de maneira quase independente e a estratégia de controle pode tirar proveito da experiência anterior. É assim que são construído os sistemas que "aprendem" e que, por conseqüência, são dotados de uma certa inteligência. A maneira como um problema deste gênero é implementado é evidentemente muito importante. As questões ligadas à representação dos dados têm um papel central.

\subsubsection{Enumeração Implícita}

\subsubsection{Introdução}

Todos os métodos de separação e avaliação podem ser considerados como métodos de enumeração implícita na medida em que não se faz nestes métodos, uma enumeração exaustiva e explícita de todas as soluções factíveis do problema tratado. 
$\mathrm{Na}$ literatura porém, o termo "enumeração implícita" é reservado aos métodos de separação e avaliação especialmente concebidos para a resolução de programas matemáticos em variáveis bivalentes $0 / 1$ ou de maneira geral aos métodos cuja codificação utilizada para os nós permite evitar o armazenamento de toda a arborescência gerada.

O algoritmo que apresentamos para a resolução de um problema por enumeração implícita não exige a resolução de nenhum programa matemático linear, como seria o caso se utilizássemos um procedimento de separação e avaliação clássico. As únicas operações que este algoritmo executa são as adições, subtrações e as multiplicações de inteiros. A exploração da arborescência de decomposição do conjunto de soluções é realizada através da busca em profundidade. As operações específicas são descritas como segue.

No algoritmo enumeração implícita fornecido no item 2.4.2.2 o problema PPI0/1 a resolver é:

$$
\begin{array}{ll}
\max & \mathrm{z}=\mathrm{cx} \\
\mathrm{s} / \mathrm{a} & \mathrm{Ax} \leq \mathrm{b} \\
& \mathrm{x}=0 / 1
\end{array}
$$

onde A é uma matriz composta de números inteiros, assim como os vetores b e c. Sem perda de generalidade, supõe todas as componentes do vetor c negativas ou nulas.

Seja $S=\{A x \leq b ; x=0 / 1\}$ o conjunto das soluções factíveis de PPI0/1. Sejam $J 1=\left\{j \in S / x_{j}=1\right\}$ e $J 0=\left\{j \in S / x_{j}=0\right\}$ dois subconjuntos disjuntos de $\{1,2, \ldots, \mathrm{n}\}$, onde $\mathrm{n}$ é o número de variáveis $0 / 1$ a determinar, e $\mathrm{JL}=\{1,2, \ldots, \mathrm{n}\} \backslash(\mathrm{J} 0 \cup$ J1) um conjunto de variáveis ditas "livres".

$O$ conjunto $S(J 1, J 0)=\left\{x \in S / x_{j}=1\right.$ se $j \in J 1, x_{j}=0$ se $\left.j \in J 0\right\}$ é uma solução de PPI0/1. A separação de um subconjunto de $\mathrm{S}(\mathrm{J} 1, \mathrm{~J} 0)$ é feita sobre uma variável arbitrária $\mathrm{x}_{\mathrm{r}}$. Assim, $\mathrm{S}(\mathrm{J} 1, \mathrm{~J} 0)$ terá dois sucessores: $\mathrm{S}(\mathrm{J} 1 \cup\{\mathrm{r}\}, \mathrm{J} 0)$ e $\mathrm{S}(\mathrm{J} 1, \mathrm{~J} 0 \cup\{\mathrm{r}\})$. 


\subsubsection{Algoritmo}

algoritmo enumeração implícita

SEPARAÇÃO: escolher o índice $r \in\{1,2, \ldots, n\}$;

CÓDIGO = [r];

$\mathrm{v}=-\infty$;

booll = true;

enquanto booll fazer

bool2 $=$ true

enquanto bool 2 = true fazer

AVALIAÇÃO: calcular $\overline{\mathrm{b}}$ e $\overline{\mathrm{z}}$;

se $\bar{Z} \leq v$ então

INTERRUPÇÃO e correção do CÓDIGO;

senão se $\bar{b} \geq 0$ então

$\mathbf{v}=\overline{\mathbf{z}}$;

SOLUÇÃO ESTOCADA;

INTERRUPÇÃO e correção do CÓDIGO;

senão TESTE;

se $t=$ true então

INTERRUPÇÃO e correção do CÓDIGO;

senão bool2 = false;

fim se

fim se

fim se

fim enquanto

se $C O ́ D I G O=\varnothing$ então

bool1 = false;

senão SEPARAÇÃO: escolher $\mathrm{r} \in\{1,2, \ldots, \mathrm{n}\} \backslash(\mathrm{J} 1 \cup \mathrm{J} 0)$;

CÓDIGO = CÓDIGO + [r] (no fim da lista);

fim se

fim enquanto

fim algoritmo. 


\subsubsection{Os Passos do Algoritmo}

As palavras em letras maiúsculas do algoritmo enumeração implícita constituem os passos fundamentais do mesmo. Neste item, tais passos são explicados de maneira detalhada:

a) Separação - A separação de um subconjunto de S(J1, J0) é feita sobre uma variável arbitrária $\mathrm{x}_{\mathrm{r}}$, onde $\mathrm{r}$ devera pertencer a J1. Uma regra para a escolha de $\mathrm{r}$ pode ser a seguinte: escolher $r$ de modo que $d_{r}=\min \left\{d_{j}\right\}$,onde:

$$
\mathrm{d}_{\mathrm{j}}=\sum_{\mathrm{i}=1}^{\mathrm{n}} \max \left\{0,-\overline{\mathrm{b}}_{\mathrm{i}}+\mathrm{a}_{\mathrm{ij}}\right\} \text { e } \mathrm{b}_{\mathrm{i}}<0
$$

$\mathrm{O}$ mínimo em $\mathrm{d}_{\mathrm{j}}$ pode ser atingido por vários índices. Escolhe-se aquele para o qual tem $\mathrm{c}^{\mathrm{r}}$ (custo) máximo

b)Avaliação - O problema de otimização PPI0/1 pode ser assim escrito:

(PPI0/1')

$$
\begin{array}{ll}
\max & \mathrm{z}-\overline{\mathrm{z}}=\mathrm{c}^{\mathrm{JL}} \mathrm{x}^{\mathrm{JL}} \\
\mathrm{s} / \mathrm{a} & \mathrm{A}^{\mathrm{L}} \mathrm{x}^{\mathrm{J}} \leq \overline{\mathrm{b}} \\
& \mathrm{x}_{\mathrm{j}}=0 / 1 \quad \mathrm{j} \in \mathrm{JL}
\end{array}
$$

onde $\quad \bar{b}=b-\sum_{j \in J 1} A^{J} \quad$ e $\quad \bar{z}=\sum_{j \in J 1} c^{J}$ 
Seja $x *$ uma solução $S(J 1, J 0)$ obtida no processo de separação. Então:

I- Se $\bar{b} \geq 0$, a solução $x *$ é factível e cx* é o novo valor da avaliação se cx* melhora a avaliação.

II- Se ao menos uma componente de $\bar{b}$ é negativa, a solução $x^{*}$ não é factível e $\mathrm{S}(\mathrm{J} 1, \mathrm{~J} 0)=\varnothing$.

c) Solução Estocada - Uma solução x* é estocada se $\mathrm{x} *$ é factível e se cx* é o novo valor da avaliação.

d) Teste - Se $\sum_{\mathrm{j} \in \mathrm{J}} \min \left\{0, \mathrm{a}_{\mathrm{rj}}\right\}>\overline{\mathrm{b}}_{\mathrm{r}}$ então $\mathrm{S}(\mathrm{J} 1, \mathrm{~J} 0)=\varnothing \quad(\mathrm{t}=$ true $)$

O teste acima permite interromper a arborescência sobre um ramo quando nenhuma atribuição das variáveis a 0 ou 1 pode satisfazer ao menos uma das restrições. Se $t=$ false então escolhe $r \in\{1,2, \ldots, n\} \backslash(J 1 \cup J 0)$.

e) Interrupção - A arborescência sobre um ramo é interrompida quando $\mathrm{S}(\mathrm{J} 1, \mathrm{~J} 0)=\varnothing$, seja por AVALIAÇÃO ou por TESTE.

f) Código - É uma lista de índices $\{1,2, \ldots, \mathrm{n}\}$ que descreve implicitamente a arborescência de decomposição de S. As variáveis cujos índices estão em J1 aparecem nesta lista seguidas do sinal $(+)$ e as variáveis cujos índices estão em J0 aparecem seguidas do sinal (-).

Quando de uma INTERRUPÇÃO da arborescência, procura-se o índice $r$ de rang mínimo com o sinal $(+)$ na lista, troca-se o sinal de r e suprime-se em CÓDIGO todos os índices de rang superior ao rang de $\mathrm{r}$. 


\subsubsection{Plano de Cortes}

\subsubsection{Introdução}

A idéia geral das técnicas de plano de cortes é o acréscimo sistemático de restrições (cortes) sempre que não haja solução inteira eliminada do conjunto de restrições .

Os algoritmos de planos de cortes resolvem um problema de programação linear inteira através de modificações efetuadas em problemas de programação linear derivados do problema original, relaxando-se as restrições de integralidade. Eles não particionam a região viável do problema relaxado em subdivisões, como nos procedimentos "branch and bound", mas sim trabalham com problemas de programação linear que são refinados pela adição de novas restrições (cortes). As novas restrições sucessivamente reduzem a região viável até que uma solução inteira ótima seja encontrada.

Para mostrar os princípios básicos do método será considerado o caso em que todas as variáveis são inteiras, assim como todos os coeficientes do problema. Esta última condição é muito menos restritiva do que parece à primeira vista, pois qualquer equação, ou inequação, constituída por coeficientes racionais, sejam eles frações, dízimas ou decimais, são equivalentes a uma expressão com coeficientes exclusivamente inteiros; somente os coeficientes irracionais é que estão excluídos do método. Cabe ressaltar que, sendo as variáveis e os coeficientes inteiros, qualquer variável de folga será, necessariamente, inteira.

Esses cortes podem ser gerados de diversas maneiras. Apresenta-se aqui as formas sugerida por Gomory e Dantzig. 


\subsubsection{Algoritmo de Cortes}

Os passos fundamentais de um algoritmo de corte são fornecidos a seguir. Nesta apresentação, PPL é um problema de programação linear e PPLI é um problema de programação linear inteira.

passo 1: Resolver o PPLI como um PPL. Se for infactível, o PPLI também o é-FIM. Se a solução do PPL é inteira o PPLI está resolvido - FIM. Caso contrário vá ao passo 2 .

passo2: De uma linha do "tableau" de resolução do PPL correspondente a uma variável restrita, mas que não apresente esta característica, derive uma nova restrição que "corte" o ponto ótimo corrente, mas que não elimine nenhuma solução inteira. Adicione a restrição ao "tableau" que será primal factível (a variável de folga na nova linha será negativa)

passo 3: Reotimize usando o método dual simplex (lexicográfico). Se o novo PPL é infactível (dual ilimitado), o PPLI também não tem solução - FIM. Se a nova solução ótima é inteira, o PPLI está resolvido-FIM. Caso contrário vá ao passo 2.

\subsubsection{Corte de Gomory}

Antes de apresentar o método dos planos de cortes, faz-se necessário introduzir a seguinte notação, onde $x$ representa um número real qualquer:

$\mathrm{n}=[x] \rightarrow$ é o maior inteiro menor ou igual a $x$, ou a parte inteira de $x$.

$\mathrm{f}=x-[x] \rightarrow$ é a parte fracionária positiva de $x, 0 \leq \mathrm{f}<1$. 
Portanto,

$$
x=[x]+\mathrm{f}=\mathrm{n}+\mathrm{f}
$$

Suponha que a solução de um problema de programação linear não seja inteira. Em particular, suponha que na i-ésima linha do 'tableau" a variável básica correspondente, $x_{\mathrm{B}_{\mathrm{i}}}$, não seja inteira. Denominando de $x_{\mathrm{N}_{\mathrm{j}}}, \mathrm{j}=1,2, \ldots, \mathrm{n}$, as variáveis não básicas, a i-ésima equação do quadro ótimo é igual a:

$$
x_{B_{i}}=b_{i}-\sum_{j=1}^{n} a_{i j} x_{N_{j}}
$$

Aplicando aos coeficientes a notação definida antes, ou seja:

$$
\begin{aligned}
& b_{i}=n_{i}+f_{i} \\
& a_{i j}=n_{i j}+f_{i j}
\end{aligned}
$$

Substituindo em 2.10, agrupando as partes inteiras e as fracionárias, temos:

$$
x_{B_{i}}=\left(n_{i}-\sum_{j=1}^{n} n_{i j} x_{N_{j}}\right)+\left(f_{i}-\sum_{j=1}^{n} f_{i j} x_{N_{i}}\right)
$$

Em 2.11 a primeira expressão entre parênteses dá um número inteiro, já que todos os elementos que participam das operações são números inteiros. Como todo $\mathrm{f}_{\mathrm{ij}}$ $\geq 0$ e todo $x_{N_{j}} \geq 0$ então:

$$
\sum_{j=1}^{n} f_{i j} x_{N_{j}} \geq 0
$$

como $\mathrm{f}_{\mathrm{i}}<1$, então 


$$
f_{i}-\sum_{j=1}^{n} f_{i j} x_{N_{j}}<1
$$

Deseja-se que $x_{B_{i}}$ seja inteiro. Como $n_{i}-\sum_{j=1}^{n} n_{i j} x_{N_{j}}$ é inteiro, logo deve-se ter $f_{i}-\sum_{j=1}^{n} f_{i j} x_{N_{j}}$ inteiro e então pode-se concluir que $f_{i}-\sum_{j=1}^{n} f_{i j} x_{N_{j}} \leq 0$ ou seja:

$$
-\sum_{j=1}^{n} f_{i j} x_{N_{j}} \leq-f_{i}
$$

A restrição 2.12 é denominada Corte Fracionário de Gomory.

\subsubsection{Corte de Dantzig}

Considere:

$$
\mathbf{x}_{\mathrm{B}_{\mathrm{i}}}+\sum_{\mathrm{j}=1}^{\mathrm{n}} \mathrm{a}_{\mathrm{ij}} \mathbf{x}_{\mathrm{N}_{\mathrm{j}}}=\mathrm{b}_{\mathrm{i}}
$$

Se cada variável não básica $\mathrm{x}_{\mathrm{j}}$ for igual a zero, então $\mathrm{x}_{\mathrm{b}}=\mathrm{y}_{0}$ será não inteiro. Se $\mathrm{x}_{\mathrm{b}}$ estiver para se tornar inteiro, então pelo menos uma das variáveis não básicas $\mathbf{x}_{\mathbf{j}}$ deverá ser diferente de zero. Tendo em vista que se requer todas as variáveis não negativas e inteiras, segue-se que pelo menos uma variável não básica deve ser maior ou igual a 1. Isto por sua vez, implica que a soma de todas as variáveis não básicas deve ser maior ou igual a 1 . Se utilizarmos esta condição como uma nova restrição a ser incorporada ao modelo de Programação Inteira original, tem-se o algoritmo de corte sugerido originalmente por Dantzig. 


\subsubsection{Programação Dinâmica}

\subsubsection{Introdução}

Elementos dinâmicos, como as considerações de tempo, são importantes em várias aplicações da Pesquisa Operacional. Nestes casos, dá-se ênfase às relações dinâmicas. Nesta dissertação interessam-nos casos determinísticos, onde cada decisão conduz a um resultado univocamente determinado.

Problemas de otimização no qual Programação Dinâmica se aplica são comumente chamados de Problemas de Otimização Dinâmica, Problemas de Controle (ou Decisão), ou Problemas de Otimização para Processos de Decisões em Vários Estágios. Os elementos essenciais do problema são os sistemas de equações que descrevem o processo a ser controlado, a função critério que avalia uma política particular de decisão, e as restrições que colocam as limitações (restrições) no sistema de operação.

O estudo realizado está concentrado na forma e nas propriedades das soluções ótimas. Estudam-se as condições que devem ser satisfeitas por um processo de decisão ótimo decomposto em estágios de tempo e desenvolvem-se técnicas de exploração para determinar a melhor ação.

Os modelos de programação dinâmica são aplicados tipicamente a problemas de pequeno ou médio porte. Os seguintes exemplos caracterizam modelos de decisão de programação dinâmica:

-regras para reencomendas de estoque indicando quando reabastecer um item e por qual quantidade.

-regras para programação da produção e uniformização da força de trabalho aplicáveis a um ambiente com demandas flutuantes.

•determinação do nível de peças de reposição para garantir a utilização com alta eficiência de equipamento de alto custo. 
-procedimento de orçamento de capital para distribuir recursos escassos a novos investimentos de riscos.

-escolha de meios de propaganda para promover ampla exposição pública ao produto de uma companhia.

•estratégia de longo prazo para substituição de bens que se depreciam.

Freqüentemente, os processos de decisão abrangidos por vários dos modelos acima podem ser de pequena dimensão. Mas muitos sistemas operacionais reais exigem milhares de decisões a cada semana. Estes modelos tem valor porque eles tornam possível tomar uma quantidade muito grande de ações através de uma abordagem de rotina. Não é necessário dizer que, mesmo se estas decisões forem inconsequentes se tomadas isoladamente, podem exercer um grande efeito nos lucros de um negócio.

A característica comum de todos os modelos de programação dinâmica consiste em expressar o problema de decisão por meio de uma formulação recursiva.

\subsubsection{O Modelo}

Considere o problema de determinar o caminho mínimo de $\mathrm{P}$ a $\mathrm{Q}$ na rede abaixo:

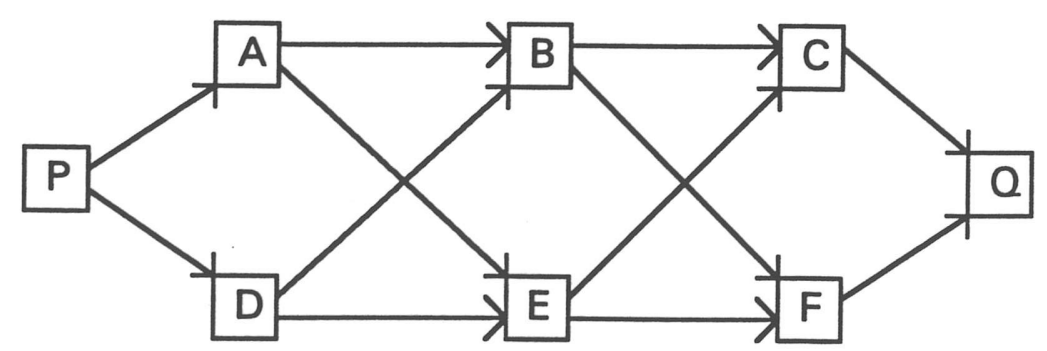

figura 2.1 - Caminho mínimo 
Uma alternativa de resolução deste problema consiste em determinar as variáveis, uma por vez, sequencialmente, decompondo o problema em uma série de estágios, cada um correspondendo a um subproblema em uma variável e resolvendo-se os vários subproblemas de uma variável separadamente em vez de se resolver o problema globalmente. Esta é a idéia básica da programação dinâmica.

Quando um problema de otimização é formulado como um problema em vários estágios a ser resolvido por programação dinâmica é conveniente introduzir-se algumas definições.

Define-se os conjuntos:

$$
\begin{aligned}
& \mathrm{K}=\{0,1,2, \ldots, \mathrm{N}\} \\
& \mathbf{K}^{\prime}=\{1,2, \ldots, \mathrm{N}-1\} . \\
& \mathbf{k}=0,1,2, \ldots, \mathrm{N}
\end{aligned}
$$

a) O sistema de equações do problema estabelece as relações entre três tipos de variáveis: as varióveis de estágio, as variáveis de estado, e as variáveis de controle ou decisão.

b) A varióvel de estágio é aquela que determina a ordem em que o evento ocorre no sistema. Esta quantidade varia monotonicamente sobre o período durante o qual as decisões são tomadas. Esta variável pode ser contínua ou discreta. Se é contínua é denotada como $t$, definida sobre $o$ intervalo $t_{0} \leq t \leq t_{f}$; enquanto se é discreta é definida como a sequência $\mathrm{k}$ (caso que trataremos).

c) As variáveis de estado descrevem completamente o sistema. Neste sentido, se os seus valores são conhecidos para todo $\mathrm{k}$, então qualquer questão sobre $\mathrm{o}$ comportamento do sistema para o alcance de $\mathrm{k}$ pode ser respondida. A escolha do conjunto de variáveis de estado para um sistema particular não é única e a determinação de um conjunto conveniente não é uma tarefa simples, dependendo da extensão e 
natureza do modelo matemático. Para indicar que $\mathrm{o}$ estado $\mathrm{x}$ ocorreu no estágio $\mathrm{k}$ denota-se $\mathrm{x}(\mathrm{k})$, (vetor $\left.\in \mathrm{R}^{\mathrm{n}}\right)$.

d) As variáveis de decisão constituem uma variável (uㅡ) que se aplicada ao sistema quando se encontra em $\mathrm{x}(\mathrm{k})$ influencia de alguma forma o estado em que o sistema se encontrará no estágio seguinte $\mathrm{x}(\mathrm{k}+1)$. Denota-se $\mathrm{u}(\mathrm{k})$ para designar $\mathrm{o}$ estágio em que ela foi aplicada $\left(\mathrm{u}(\mathrm{k})\right.$ é vetor $\in \mathrm{R}^{\mathrm{m}}$ ).

e) Conjunto de estado viáveis é o conjunto dos estados que $\mathrm{x}$ pode assumir no estágio $\mathrm{k}\left(\mathrm{X}(\mathrm{k}) \subset \mathrm{R}^{\mathrm{n}}\right)$. O numero de elementos de $\mathrm{X}(\mathrm{k})$ é sempre finito.

f) Conjunto de decisões admissiveis é o conjunto das decisões que podem atuar sobre o sistema quando ele se encontra no estágio k e no estado x. Denotaremos por $\mathrm{U}(\mathrm{x}, \mathrm{k})\left(\in \mathrm{R}^{\mathrm{m}}\right.$ e é um conjunto finito).

g) Equações recursivas do sistema é uma equação que descreve a relação entre o estado e um dado estágio, a decisão então aplicada e o novo estado resultante.

$$
\begin{aligned}
\mathrm{R}^{\mathrm{n}} \times \mathrm{R}^{\mathrm{m}} \mathrm{xN} \stackrel{\mathrm{f}}{\longrightarrow} \mathrm{R}^{\mathrm{n}} \\
\mathrm{f}:(\mathrm{x}(\mathrm{k}), \mathrm{u}(\mathrm{k}), \mathrm{k}) \mapsto \mathrm{f}(\mathrm{x}(\mathrm{k}), \mathrm{u}(\mathrm{k}), \mathrm{k})=\mathrm{x}(\mathrm{k}+1)
\end{aligned}
$$

h) Custo elementar - custo elementar devido à atuação da decisão admissível u ao sistema, quando este se encontra no estágio $\mathrm{k}$ e no estado viável $\mathrm{x}$ :

$$
\begin{gathered}
\mathrm{R}^{\mathrm{n}} \times \mathrm{R}^{\mathrm{m}} \mathrm{xN} \stackrel{\ell}{\longrightarrow} \mathrm{R} \\
\ell:(\mathrm{x}(\mathrm{k}), \mathrm{u}(\mathrm{k}), \mathrm{k}) \mapsto \ell(\mathrm{x}(\mathrm{k}), \mathrm{u}(\mathrm{k}), \mathrm{k})
\end{gathered}
$$

Observação: Convém notar que: 
1) frequentemente confunde-se a função custo elementar com seu valor assumido em determinado ponto de seu domínio;

2) não houve preocupação em se definir o domínio das funções $\mathrm{f}$ e $\ell$ porque é bem mais complicado do que se parece a primeira vista (voltaremos ao assunto posteriormente).

i) Estado inicial - é o estado em que se encontra o sistema no estágio inicial (k =0). Esse estado é único, i.e., $X(0)=\{x(0)\}$

j) Política admissivel aplicada a $\overline{\mathbf{x}}=x\left(\mathbf{k}_{0}\right) \in X\left(\mathbf{k}_{0}\right), \mathbf{k}_{0} \in \mathbf{K}^{\prime}$ - é uma sequência de decisões $[u(k)]_{k_{0}}^{N-1}=\left(u\left(k_{0}\right), u\left(k_{0}+1\right), \ldots, u(N-1)\right)$ tal que, se definirmos:

$$
x(k+1)=f(x(k), u(k), k), \quad k=k_{0}, k_{0}+1, \ldots, N-1
$$

então:

$$
\begin{array}{ll}
\text { 1) } u(k) \in U(x(k), k) & k=k_{0}, k_{0}+1, \ldots, N-1 \\
\text { 2) } x(k) \in X(k) & k=k_{0}+1, k_{0}+2, \ldots, N
\end{array}
$$

Ao conjunto das políticas admissíveis em $\overline{\mathrm{x}}=\mathrm{x}\left(\mathrm{k}_{0}\right)$ notamos por $\Omega\left(\overline{\mathrm{x}}, \mathrm{k}_{0}\right)$.

k) Trajetória - trajetória gerada por uma política $[\mathrm{u}(\mathrm{k})]_{\mathrm{k}_{0}}^{\mathrm{N}-1}$ admissível em $\overline{\mathrm{x}}=$ $x\left(k_{0}\right)$ é o conjunto dos pontos $(k, x(k))$, onde:

$$
\begin{aligned}
& \mathrm{k}=\mathrm{k}_{0}, \mathrm{k}_{0}+1, \ldots, \mathrm{N}-1 \\
& \mathrm{x}(\mathrm{k}+1)=\mathrm{f}(\mathrm{x}(\mathrm{k}), \mathrm{u}(\mathrm{k}), \mathrm{k}) \quad \mathrm{k}=\mathrm{k}_{0}, \mathrm{k}_{0}+1, \ldots, \mathrm{N}-1
\end{aligned}
$$


1)Critério - é a função j abaixo descrita

$$
\mathrm{J}:\left(\mathrm{x}\left(\mathrm{k}_{0}\right),[\mathrm{u}(\mathrm{k})]_{\mathrm{k}_{0}}^{\mathrm{N}-1}, \mathrm{k}_{0}\right) \mapsto \sum_{\mathrm{k}=\mathrm{k}_{0}}^{\mathrm{N}-1} \ell(\mathrm{x}(\mathrm{k}), \mathrm{u}(\mathrm{k}), \mathrm{k})
$$

onde

$$
\begin{aligned}
& {[\mathrm{u}(\mathrm{k})]_{\mathrm{k}_{0}}^{\mathrm{N}-1} \in \Omega\left(\mathrm{x}\left(\mathrm{k}_{0}\right), \mathrm{k}_{0}\right) \mathrm{e}} \\
& \mathrm{x}(\mathrm{k}+1)=\mathrm{f}(\mathrm{x}(\mathrm{k}), \mathrm{u}(\mathrm{k}), \mathrm{k}) \quad \mathrm{k}=\mathrm{k}_{0}, \mathrm{k}_{0}+1, \ldots, \mathrm{N}-1
\end{aligned}
$$

m) Alvo - é o conjunto $\mathrm{X}(\mathrm{N})$. Ao contrário do que ocorreu com o estado inicial, o alvo pode ser constituído por mais de um estado viável.

Observação: Alguns problemas podem ter associado ao alvo, um custo terminal. $\mathrm{Na}$ prática isto nada altera nossa análise, basta aumentar para $\mathrm{N}+1$ o número de estágios e estes custos terminais passam a ser considerados como custos elementares comuns.

n) Problema de Programação Dinâmica - encontrar se existir, uma política admissível $[\hat{\mathrm{u}}(\mathrm{k})]_{0}^{\mathrm{N}-1}$ que aplicada a $\mathrm{x}(0)$, leva o sistema ao estágio $\mathrm{N}$ minimizando (ou maximizando) o valor da função critério, i.e.,

$$
\begin{gathered}
\mathrm{J}\left(\mathrm{x}(0),[\overline{\mathrm{u}}(\mathrm{k})]_{0}^{\mathrm{N}-1}, 0\right)=\frac{\min \mathrm{J}\left(\mathrm{x}(0),[\mathrm{u}(\mathrm{k})]_{0}^{\mathrm{N}-1}, 0\right)}{[\mathrm{u}(\mathrm{k})]_{0}^{\mathrm{N}-1} \in \Omega(\mathrm{x}(0), 0)}
\end{gathered}
$$

Obs.: Se existir uma política admissível, então existe uma política ótima $[\overline{\mathrm{u}}(\mathrm{k})]_{0}^{\mathrm{N}-1}$, pois o número de políticas admissíveis não pode ser infinito. 


\subsubsection{Princípio da Otimalidade}

Princípio da Otimalidade - $\mathrm{Se}[\overline{\mathrm{u}}(\mathrm{k})]_{\mathrm{k}_{0}}^{\mathrm{N}-1}, \mathrm{k}_{0} \in \mathrm{K}^{\prime}$, é uma política ótima considerando-se $\mathbf{x}\left(\mathrm{k}_{0}\right)$ como estado inicial, então $[\overline{\mathrm{u}}(\mathrm{k})]_{\mathrm{k}_{0}+1}^{\mathrm{N}-1}$ será uma política ótima considerando-se $x\left(k_{0}+1\right)=f\left(x\left(k_{0}\right), \bar{u}\left(k_{0}\right), k_{0}\right)$ como estado inicial.

\section{Demonstração:}

Seja $\mathbf{k}_{0} \in \mathbf{K}^{\prime}$ e define-se: $\quad \overline{\mathbf{x}}=\mathbf{x}\left(\mathbf{k}_{0}\right) \in \mathrm{X}\left(\mathrm{k}_{0}\right)$

$$
\begin{aligned}
& \overline{\mathrm{J}}\left(\overline{\mathrm{x}}, \mathrm{k}_{0}\right) \stackrel{\Delta}{=} \mathrm{J}\left(\overline{\mathrm{x}},[\overline{\mathrm{u}}(\mathrm{k})]_{\mathrm{k}_{0}}^{\mathrm{N}-1}, \mathrm{k}_{0}\right)=\min _{[\mathrm{u}(\mathrm{k})]_{\mathrm{k}_{0}}^{\mathrm{N}-1} \in \Omega\left(\overline{\mathrm{x}}, \mathrm{k}_{0}\right)} \mathrm{J}\left(\overline{\mathrm{x}},[\mathrm{u}(\mathrm{k})]_{\mathrm{k}_{0}}^{\mathrm{N}-1}, \mathrm{k}_{0}\right) \\
&= \min \sum_{\mathrm{k}=\mathrm{k}_{0}}^{\mathrm{N}-1} \ell(\mathrm{x}(\mathrm{k}), \mathrm{u}(\mathrm{k}), \mathrm{k}) \\
& {[\mathrm{u}(\mathrm{k})]_{\mathrm{k}_{0}}^{\mathrm{N}-1} \in \Omega\left(\overline{\mathrm{x}}, \mathrm{k}_{0}\right) }
\end{aligned}
$$

onde

$$
x(k+1)=f(x(k), u(k), k) \quad k=k_{0}, k_{0}+1, \ldots, N-1
$$

Então, por definição:

$$
\overline{\mathrm{J}}\left(\overline{\mathrm{x}}, \mathrm{k}_{0}\right)=\min _{[\mathrm{u}(\mathrm{k})]_{\mathrm{k}_{0}}^{\mathrm{N}-1} \in \Omega\left(\overline{\mathrm{x}}, \mathrm{k}_{0}\right)}\left\{\ell\left(\overline{\mathrm{x}}, \mathrm{u}\left(\mathrm{k}_{0}\right), \mathrm{k}_{0}\right)+\mathrm{J}\left(\mathrm{x}\left(\mathrm{k}_{0}+1\right),[\mathrm{u}(\mathrm{k})]_{\mathrm{k}_{0}+1}^{\mathrm{N}-1}, \mathrm{k}_{0}+1\right)\right\}
$$


Admite-se por absurdo que existe uma sequência $[\widetilde{\mathrm{u}}(\mathrm{k})]_{\mathrm{k}_{0}+1}^{\mathrm{N}-1}$ $\in \Omega\left(\widetilde{\mathbf{x}}, \mathbf{k}_{0}+1\right)$, onde

$$
\widetilde{\mathbf{x}}=\mathrm{f}\left(\overline{\mathrm{x}}, \overline{\mathrm{u}}\left(\mathrm{k}_{0}\right), \mathrm{k}_{0}\right) \text {, }
$$

tal que

$$
\mathrm{J}\left(\widetilde{\mathrm{x}},[\widetilde{\mathrm{u}}(\mathrm{k})]_{\mathrm{k}_{0}+1}^{\mathrm{N}-1}, \mathrm{k}_{0}+1\right)<\mathrm{J}\left(\widetilde{\mathrm{x}},[\overline{\mathrm{u}}(\mathrm{k})]_{\mathrm{k}_{0}+1}^{\mathrm{N}-1}, \mathrm{k}_{0}+1\right)
$$

Define-se:

$$
\left[\mathrm{u}^{\prime}(\mathrm{k})\right]_{\mathrm{k}_{0}}^{\mathrm{N}-1}=\left\{\overline{\mathrm{u}}\left(\mathrm{k}_{0}\right), \widetilde{\mathrm{u}}\left(\mathrm{k}_{0}+1\right), \widetilde{\mathrm{u}}\left(\mathrm{k}_{0}+2\right), \ldots, \widetilde{\mathrm{u}}(\mathrm{N}-1)\right\}
$$

então fica evidente que:

$$
\left[\mathrm{u}^{\prime}(\mathrm{k})\right]_{\mathrm{k}_{0}}^{\mathrm{N}-1} \in \Omega\left(\overline{\mathrm{x}}, \mathrm{k}_{0}\right)
$$

e além disso:

$$
\mathrm{J}\left(\overline{\mathrm{x}},\left[\mathrm{u}^{\prime}(\mathrm{k})\right]_{\mathrm{k}_{0}}^{\mathrm{N}-1}, \mathrm{k}_{0}\right)<\overline{\mathrm{J}}\left(\overline{\mathrm{x}}, \mathrm{k}_{0}\right)
$$

o que é absurdo, pois contraria a definição de $\overline{\mathrm{J}}\left(\overline{\mathrm{x}}, \mathrm{k}_{\mathbf{0}}\right)$.

Pode-se então afirmar que:

$$
\begin{gathered}
\mathrm{J}\left(\widetilde{\mathrm{x}},[\overline{\mathrm{u}}(\mathrm{k})]_{\mathrm{k}_{0}+1}^{\mathrm{N}}, \mathrm{k}_{0}+1\right)=\min _{[\mathrm{u}(\mathrm{k})]_{\mathrm{k}_{0}+1}^{\mathrm{N}-1} \in \Omega\left(\widetilde{\mathrm{x}}, \mathrm{k}_{0}+1\right)} \mathrm{J}\left(\widetilde{\mathrm{x}},[\mathrm{u}(\mathrm{k})]_{\mathrm{k}_{0}+1}^{\mathrm{N}-1}, \mathrm{k}_{0}+1\right)=\overline{\mathrm{J}}\left(\widetilde{\mathrm{x}}, \mathrm{k}_{0}+1\right)
\end{gathered}
$$

concluindo então que

$$
\begin{aligned}
\overline{\mathrm{J}}\left(\overline{\mathbf{x}}, \mathrm{k}_{0}\right)= & \min _{\mathrm{u}\left(\mathrm{k}_{0}\right) \in \mathrm{U}\left(\overline{\mathrm{x}}, \mathrm{k}_{0}\right)}\left\{\ell\left(\overline{\mathrm{x}}, \mathrm{u}\left(\mathrm{k}_{0}\right), \mathrm{k}_{0}\right)+\overline{\mathrm{J}}\left(\mathrm{f}\left(\overline{\mathrm{x}}, \mathrm{u}\left(\mathrm{k}_{0}\right), \mathrm{k}_{0}\right), \mathrm{k}_{0}+1\right)\right\} \\
& \mathbf{f}\left(\overline{\mathrm{x}}, \mathrm{u}\left(\mathrm{k}_{0}\right), \mathrm{k}_{0}\right) \in \mathrm{X}\left(\mathrm{k}_{0}+1\right)
\end{aligned}
$$

Essa equação é chamada Equação Recursiva de Otimalidade. 
Por trás do complicado formalismo da demonstração encontra-se uma idéia bastante simples. O que o princípio da otimalidade afirma é que, o valor de uma política ótima faltando atingir $\mathbf{n}$ estágios depende da consequência econômica da ação imediata e do valor correspondente de uma política ótima com n-1 estágios restantes.

\subsubsection{Comentários}

i)Na literatura, a respeito de Programação Dinâmica, encontra-se a seguinte nomenclatura:

$$
\begin{aligned}
& \text { decisão }=\text { controle } \\
& \text { critério }=\text { objetivo } \\
& \text { política }=\text { estratégia }
\end{aligned}
$$

ii)Uma formulação completa dos elementos do P.P.D. encontra algumas dificuldades. As principais são relativas à descrição do domínio das funções $\underline{f}, \underline{\ell}$ e $\underline{J}$. Para se ter uma idéia das dificuldades que surgem, tenta-se definir o domínio de $\mathrm{f}$. Antes, convém notar que uma solução admissível não necessariamente levará o sistema a um novo estado viável, mas isto não preocupa, pois não se esta interessados com a imagem de $\mathrm{f}$.

A primeira idéia para definir o domínio de fé:

$$
\mathrm{F}: \mathrm{X}(\mathrm{k}) \times \mathrm{U}(\mathrm{x}(\mathrm{k}), \mathrm{k}) \times \mathrm{K}^{\prime} \rightarrow \mathrm{R}^{\mathrm{n}}
$$

Que não é possível, pois o conjunto $\mathrm{X}(\mathbf{k})$ vai depender de $\mathbf{k} \in \mathbf{K}^{\prime}$ escolhido, e mais ainda o $\mathrm{U}(\mathrm{x}(\mathrm{k}), \mathrm{k})$ vai depender do $\mathrm{k}$ e do $\mathrm{x}(\mathrm{k})$ escolhidos. Assim o domínio vai depender de um elemento do próprio domínio, o que não é correto. Então, define-se o domínio de $\mathrm{f}$ como sendo o conjunto:

$$
\left\{(\mathrm{x}(\mathrm{k}), \mathrm{u}(\mathrm{k}), \mathrm{k}) / \mathrm{k} \in \mathrm{K}^{\prime}, \mathrm{x}(\mathrm{k}) \in \mathrm{X}(\mathrm{k}), \mathrm{u}(\mathrm{k}) \in \mathrm{U}(\mathrm{x}(\mathrm{k}), \mathrm{k})\right\}
$$


Essa definição apesar de correta é bem complicada e não fornece nenhuma informação de interesse, e é por isso que preferimos omiti-la. Na prática, nunca haverá dúvida se $(\mathrm{x}(\mathrm{k}), \mathrm{u}(\mathrm{k}), \mathrm{k})$ pertence ou não ao domínio de $\mathrm{f}$.

Os domínio de $\ell$ e J são respectivamente:

$$
\left\{(\mathrm{x}(\mathrm{k}), \mathrm{u}(\mathrm{k}), \mathrm{k}) / \mathrm{k} \in \mathrm{K}^{\prime}, \mathrm{x}(\mathrm{k}) \in \mathrm{X}(\mathrm{k}), \mathrm{u}(\mathrm{k}) \in \mathrm{U}(\mathrm{x}(\mathrm{k}), \mathrm{k})\right\}
$$

$$
\left\{\left(\mathrm{x}\left(\mathrm{k}_{0}\right),[\mathrm{u}(\mathrm{k})]_{\mathrm{k}_{0}}^{\mathrm{N}-1}, \mathrm{k}_{0}\right) / \mathrm{k}_{0} \in \mathrm{K}^{\prime}, \mathrm{x}\left(\mathrm{k}_{0}\right) \in \mathrm{X}\left(\mathrm{k}_{0}\right),[\mathrm{u}(\mathrm{k})]_{\mathrm{k}_{0}}^{\mathrm{N}-1} \in \Omega\left(\mathrm{x}\left(\mathrm{k}_{0}\right), \mathrm{k}_{0}\right)\right\}
$$

iii)O princípio da otimalidade é aplicado a funções critério bem mais gerais do que a considerada na seção anterior, que foi

$$
\begin{aligned}
\mathrm{J}\left(\mathrm{x}\left(\mathrm{k}_{0}\right),[\mathrm{u}(\mathrm{k})]_{\mathrm{k}_{0}}^{\mathrm{N}-1}, \mathrm{k}_{0}\right)=\ell\left(\mathrm{x}\left(\mathrm{k}_{0}\right), \mathrm{u}\left(\mathrm{k}_{0}\right), \mathrm{k}_{0}\right)+ \\
\quad+\ell\left(\mathrm{x}\left(\mathrm{k}_{0}+1\right), \mathrm{u}\left(\mathrm{k}_{0}+1\right), \mathrm{k}_{0}+1\right)+\ldots+\ell(\mathrm{x}(\mathrm{N}-1), \mathrm{u}(\mathrm{N}-1), \mathrm{N}-1)
\end{aligned}
$$

ou seja, uma soma de custo elementares.

O princípio aplica-se a funções do tipo

$$
\begin{aligned}
\mathrm{J}\left(\mathrm{x}\left(\mathrm{k}_{0}\right),[\mathrm{u}(\mathrm{k})]_{\mathrm{k}_{0}}^{\mathrm{N}-1}, \mathrm{k}_{0}\right)=\mathrm{g}\left(\ell\left(\mathrm{x}\left(\mathrm{k}_{0}\right), \mathrm{u}\left(\mathrm{k}_{0}\right), \mathrm{k}_{0}\right),\right. \\
\left.\quad \ell\left(\mathrm{x}\left(\mathrm{k}_{0}+1\right), \mathrm{u}\left(\mathrm{k}_{0}+1\right), \mathrm{k}_{0}+1\right), \ldots, \ell(\mathrm{x}(\mathrm{N}-1), \mathrm{u}(\mathrm{N}-1), \mathrm{N}-1)\right)
\end{aligned}
$$

desde que g satisfaça algumas restrições. Formalizando, tem-se o seguinte teorema:

Teorema: Se

a) g é uma função separável, i.e., pode ser escrita sob a forma (simplificando a notação)

$$
\mathrm{g}\left(\ell_{\mathrm{k}_{0}}, \ell_{\mathrm{k}_{0}+1}, \ldots, \ell_{\mathrm{N}-1}\right)=\mathrm{h}_{1}\left(\ell_{\mathrm{k}_{0}}, \mathrm{~h}_{2}\left(\ell_{\mathrm{k}_{0}+1}, \ldots, \ell_{\mathrm{N}-1}\right)\right)
$$


onde

$$
\begin{aligned}
& \mathrm{R}^{\mathrm{N}-\mathrm{k}_{0}} \stackrel{\mathrm{g}}{\longrightarrow} \mathrm{R}, \\
& \mathrm{R}^{2} \stackrel{\mathrm{h}_{1}}{\longrightarrow} \mathrm{R}, \\
& \mathrm{R}^{\mathrm{N}-1-\mathrm{k}_{0}} \stackrel{\mathrm{h}_{2}}{\longrightarrow} \mathrm{R}
\end{aligned}
$$

b)para cada $\ell_{\mathrm{k}_{0}}, \mathrm{~h}_{1}$ é uma função monotonicamente não decrescente de $\mathrm{h}_{2}\left(\ell_{\mathrm{k}_{0}+1}, \ldots, \ell_{\mathrm{N}-1}\right)$ então:

c) $\quad \min \quad \mathrm{g}\left(\ell_{\mathrm{k}_{0}}, \ell_{\mathrm{k}_{0}+1}, \ldots, \ell_{\mathrm{N}-1}\right)=$

$$
\begin{aligned}
& \quad[\mathrm{u}(\mathrm{k})]_{\mathrm{k}_{0}}^{\mathrm{N}-1} \in \Omega\left(\mathrm{x}\left(\mathrm{k}_{0}\right), \mathrm{k}_{0}\right) \\
& =\min _{\mathrm{u}\left(\mathrm{k}_{0}\right) \in \mathrm{U}\left(\mathrm{x}\left(\mathrm{k}_{0}\right), \mathrm{k}_{0}\right)} \mathrm{h}_{1}\left(\ell_{\mathrm{k}_{0}}, \quad \min \mathrm{h}_{2}\left(\ell_{\mathrm{k}_{0}+1}, \ldots, \ell_{\mathrm{N}-1}\right)\right) \\
& \left.\mathrm{x}\left(\mathrm{k}_{0}+1\right)=\mathrm{f}(\mathrm{k})\right]_{\mathrm{k}_{0}+1}^{\mathrm{N}-1} \in \Omega\left(\mathrm{x}\left(\mathrm{k}_{0}+1\right), \mathrm{k}_{0}+1\right) \\
& \mathrm{k}
\end{aligned}
$$

A demonstração desse teorema segue as mesmas linhas gerais do teorema da seção anterior, que é um caso particular do acima enunciado.

\subsubsection{Os Problemas de Grande Porte}

Seja o problema:

$$
\begin{array}{ll}
\text { minimizar } & F=\sum_{k=0}^{N-1} J(x(k), u(k), k)+\Gamma(x(N)) \\
s / a & x(k+1)=f(x(k), u(k), k), \quad x(k) \in X(k), u(k) \in U(k)
\end{array}
$$


Uma comparação entre esforços computacionais requeridos em Programação Dinâmica e na Enumeração Completa é realizada abaixo:

\section{a) Programação Dinâmica}

Um PPD pode ser resolvido de maneira "FORWARD" ou "BACKWARD", obtendo-se o mesmo resultado e realizando-se o mesmo esforço computacional. Seja um PPD resolvido "BACKWARD", onde:

$$
\begin{aligned}
& N-n^{\circ} \text { de estágios. } \\
& N_{e}-n^{\circ} \text { de estados em cada estágio. } \\
& N_{c}-n^{\circ} \text { de controles (decisão) em cada estado. }
\end{aligned}
$$

Pela equação recursiva, para um estado fixado, tem-se necessidade de uma adição por controle:

$$
\begin{aligned}
& \text { - por estado } \rightarrow \mathrm{N}_{\mathrm{c}} \text { adições } \\
& \text { - por estágio } \rightarrow \mathrm{N}_{\mathrm{e}} * \mathrm{~N}_{\mathrm{c}} \text { adições } \\
& \text { - no total } \rightarrow \mathrm{N} * \mathrm{~N}_{\mathrm{e}} * \mathrm{~N}_{\mathrm{c}} \text { adições }
\end{aligned}
$$

Em cada estado, realizam-se $\left(\mathrm{N}_{\mathrm{c}}-1\right)$ comparações, e no total $\mathrm{N}^{*} \mathrm{~N}_{\mathrm{e}} *\left(\mathrm{~N}_{\mathrm{c}}-1\right)$ comparações

\section{b) Enumeração Completa}

Um Processo de enumeração completa pode ser compreendido através da visualização da Figura abaixo: 


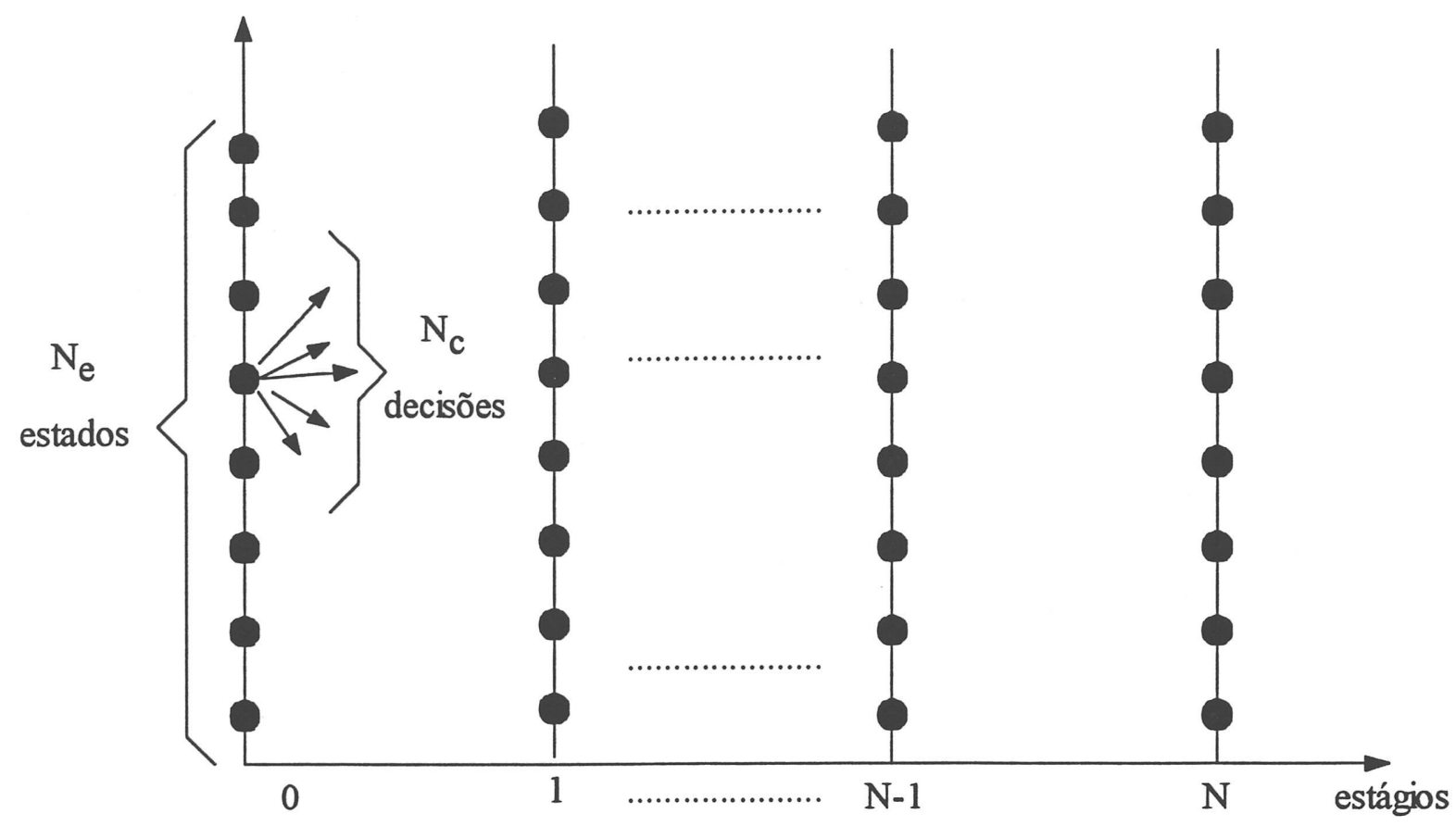

figura 2.2 Enumeração Completa.

A partir de cada $\mathrm{x}_{0}$ tem-se $\underbrace{\mathrm{N}_{\mathrm{c}} * \mathrm{~N}_{\mathrm{c}} * \ldots * \mathrm{~N}_{\mathrm{c}}}_{\mathrm{N} \text { fatores }}$ trajetórias.

Como temos $\mathrm{N}_{\mathrm{e}}$ valores diferentes para $\mathrm{x}_{0}$, resultam:

$$
\mathrm{N}_{\mathrm{e}} * \mathrm{~N}_{\mathrm{c}}^{\mathrm{N}} \text { trajetórias distintas }
$$

$\mathrm{O}$ custo de cada trajetória é calculado fazendo-se a soma de $\mathrm{N}+1$ fatores

$$
\begin{aligned}
& \mathrm{J}_{0}+\mathrm{J}_{1}+\ldots+\mathrm{J}_{\mathrm{N}-1}+\Gamma \\
& \Rightarrow \mathrm{N} * \mathrm{~N}_{\mathrm{e}} * \mathrm{~N}_{\mathrm{c}}^{\mathrm{N}} \quad \text { adições }
\end{aligned}
$$

Para se obter a solução ótima, deve-se comparar os custos das trajetórias duas a duas:

$$
\left(\mathrm{N}_{\mathrm{e}} * \mathrm{~N}_{\mathrm{c}}^{\mathrm{N}}-1\right) \quad \text { comparações }
$$




\section{c) Comparação das Duas Técnicas}

Seja:

$$
\begin{aligned}
& \mathrm{N}=12 \\
& \mathrm{~N}_{\mathrm{c}}=10 \\
& \mathrm{~N}_{\mathrm{e}}=100 \\
& \mathrm{~T}_{\text {soma }}=\mathrm{T}_{\text {comparação }}=10^{-9} \mathrm{~s}
\end{aligned}
$$

A comparação entre a Programação Dinâmica e a enumeração completa para os valores fornecidos anteriormente é fornecida na tabela 2.1.

\begin{tabular}{|c|c|c|c|}
\cline { 2 - 4 } \multicolumn{1}{c|}{} & Adições & Comparações & Tempo \\
\hline P. D. & 12.000 & 10.800 & $23 \mu \mathrm{s}$ \\
\hline E. C. & $12 * 10^{14}$ & $10^{14}$ & 15 dias \\
\hline
\end{tabular}

Tabela 2.2 Comparação dos esforços computacionais das duas técnicas.

Seja:

$$
\begin{aligned}
& \mathrm{N}=12 \\
& \mathrm{~N}_{\mathrm{c}}=25 \\
& \mathrm{~N}_{\mathrm{e}}=100
\end{aligned}
$$

Para estes novos valores temos a comparação na tabela 2.2.

\begin{tabular}{|c|c|c|c|}
\cline { 2 - 4 } \multicolumn{1}{c|}{} & Adições & Comparações & Tempo \\
\hline P. D. & 30.000 & 28.800 & $59 \mu \mathrm{s}$ \\
\hline E. C. & $7,1^{*} 10^{19}$ & $6,0^{*} 10^{18}$ & 24 séculos \\
\hline
\end{tabular}

Tabela 2.3 Comparação dos esforços computacionais das duas técnicas. 
Para $\mathrm{N}=12$ e um número crescente de variáveis de estado de controle, a tabela

\begin{tabular}{|c|c|c|c|c|c|c|}
\hline $\begin{array}{c}\mathrm{N}^{0} \text { de } \\
\text { variáveis } \\
\text { de estado }\end{array}$ & $\begin{array}{c}\mathrm{N}^{0} \text { de } \\
\text { variáveis d } \\
\text { controle }\end{array}$ & $\mathrm{N}_{\mathrm{e}}$ & $\mathrm{N}_{\mathrm{c}}$ & Adições & Comparações & Tempo \\
\hline 1 & 1 & 100 & 25 & 30.000 & 28.800 & $59 \mu \mathrm{s}$ \\
2 & 2 & $10^{4}$ & 625 & $75^{*} 10^{6}$ & $75^{*} 10^{6}$ & $150 \mathrm{~ms}$ \\
3 & 3 & $10^{6}$ & 15.625 & $1.875^{*} 10^{8}$ & $1875^{*} 10^{8}$ & $6 \mathrm{~min}$ \\
4 & 4 & $10^{8}$ & 390.625 & $4,7^{*} 10^{14}$ & $4,7^{*} 10^{14}$ & $260 \mathrm{~h}$ \\
\hline
\end{tabular}

Tabela 2.4 Esforços computacionais requeridos na Programação Dinâmica

2.3 mostra o expressivo aumento no valor de tempo computacional quando o número de variáveis de estado e de controle aumentam. Tal comportamento é chamado na literatura de "maldição da dimensionalidade" da Programação Dinâmica.

\subsubsection{Avaliação da Técnica}

A abordagem de programação dinâmica resolve problema de otimização com múltiplas restrições e muitas variáveis dividindo-se o problema em uma seqüência de estágios nos quais é realizada uma otimização de dimensão inferior. Em contraste, a maioria das abordagens de programação linear e outras não-lineares tentam resolver tais problemas considerando-se todas as restrições simultaneamente.

A abordagem de programação dinâmica molda um problema dentro da seguinte estrutura:

i) as variáveis de decisão com suas restrições correspondentes são agrupadas em estágios e os estágios são considerados seqüencialmente, 
ii) as únicas informações sobre os estágios anteriores que são relevantes para selecionar valores ótimos para as variáveis de decisão correntes são condensadas em uma variável chamada de estado, que pode ser n-dimensional,

iii) a decisão corrente, dado o estado presente do sistema, tem uma influência previsível sobre o estado do próximo estágio,

iv) a otimalidade da decisão corrente é julgada em termos de seu impacto econômico previsto sobre o estágio atual e todos os estágios subseqüentes.

Para os vários problemas, a programação dinâmica oferece uma ampla melhoria sobre a enumeração completa de todas as possibilidades. A viabilidade dessa técnica depende de modo crítico das dimensões da variável de estado, e esta é uma razão da necessidade em se ter habilidade na formulação. A diferença entre uma formulação grosseira e uma talentosa pode ser 0 fator decisivo na viabilidade dessa abordagem[Wagner, 1986].

A Programação Dinâmica pode ser aplicada a problemas de pequena escala nãolineares e de valores inteiros. Por não existir nenhuma forma canônica satisfatória para todos estes modelos, não existe um programa eficiente para manipular todos os problemas de programação dinâmica. Mas a forma de recursão de programação dinâmica é comumente bastante simples, de modo que não dá muito trabalho escrever um programa para o modelo específico a ser resolvido.

\subsubsection{Heurísticas}

Um algoritmo aproximado ou heurístico permite a obtenção de uma solução factível, mas não necessariamente ótima para um certo problema dado. Tal algoritmo pode ser útil em diferentes casos, por exemplo :

1) para a resolução de um problema não polinomial de grande porte, 
2) para fornecer uma boa solução de partida para inicializar um outro algoritmo exato,

3) para encontrar uma "boa" solução para um problema prático cujos dados (restrições, função-objetivo) não estejam definidos de maneira precisa, e que podem, aliás, estar carregados de erros de medições.

\subsubsection{Heurísticas Gulosas}

As heurísticas gulosas ("greedy") caracterizam-se pelo fato de jamais questionar uma decisão tomada anteriormente. A otimalidade de uma solução assim obtida não pode, evidentemente, ser assegurada, mas deve-se observar que os algoritmos gulosos de Prim e Kruskal para a busca de uma árvore de peso mínimo (ou máximo) em um grafo (Gondran e Minoux 1985, Sakarovitch, 1984), entre outros algoritmos igualmente gulosos, conduzem à solução ótima. Tal comportamento é devido à estrutura particular do problema de árvore de peso mínimo, caracterizada como um matróide (Gondran e Minoux, 1985).

O algoritmo abaixo (Sakarovitch, 1984) é uma heurística gulosa para a resolução do problema da mochila. Seja $n$ o número de variáveis $0 / 1$ a determinar e $\mathrm{xj}$, $\mathrm{cj}$, aj e b respectivamente o vetor das variáveis inteiras do problema, o vetor custo associado às variáveis, o vetor de restrição tecnológica e o vetor de recursos.

algoritmo mochila guloso

reindexação das variáveis de modo a ter-se : $c_{1} / a_{1} \geq c_{2} / a_{2} \geq \ldots . \geq c_{n} / a_{n}$ para $j=1$ a $n$ fazer

$\mathbf{x j}_{\mathbf{j}}=0$

se $a j<b$ então

$$
\begin{aligned}
& x j=1 \\
& b=b-a j
\end{aligned}
$$

fim se

fim para

fim algoritmo mochila guloso 


\subsubsection{Aproximação Local}

A partir de uma solução factível $s$ do problema de otimização combinatória considerado, define-se uma vizinhança $\mathrm{V}(\mathrm{s})$ desta solução e procura-se melhorar o valor de s em V(s). Se uma solução de melhor qualidade é encontrada, troca-se s por s' e recomeça-se o procedimento. Caso contrário, fim: obteve-se um ótimo local para o problema.

Como exemplo da aplicação deste procedimento, seja o problema da bipartição : Considere uma rede $R=(X, E, c)$, onde $(X, E)$ é um grafo não orientado sobre $|X|=2 n$ nós e c $: E \rightarrow N$. Trata-se de particionar $X$ em dois subconjuntos $X^{\prime}$ e $X^{\prime \prime}$ com $\left|X^{\prime}\right|=$ $\left|X^{\prime \prime}\right|$ de tal maneira que $S[c(e)]$ tenha valor mínimo $\left\{e=(x, y) \mid x \in X^{\prime}\right.$ e $\left.y \in X^{\prime \prime}\right\}$. A partir de uma solução $X$ ', procura-se determinar se existe uma troca de um elemento de $X^{\prime}$ por outro de $X^{\prime \prime}$ (ou vice-versa) capaz de diminuir o valor da função-objetivo. Podese também imaginar a troca de um par (ou mais geralmente de uma k-upla) de elementos. Este problema tem aplicações no projeto de circuitos integrados quando quer-se minimizar o número de conexões do circuito.

\subsubsection{Esquemas de Aproximação}

Os esquemas de aproximação são formados por famílias de métodos aproximativos nas quais o erro cometido em uma solução obtida é limitado por um teto fixado.

Definição : A família de algoritmo Ae constitui um "esquema de aproximação" para a resolução de um problema $P$ se, qualquer que seja e $>0, A_{e}$ é uma eaproximação. 
Observação: O esquema de aproximação $A_{e}$ é "polinomial" se para todo valor de $e$ o algoritmo $A_{e}$ é polinomial. O esquema de aproximação é "completamente polinomial" se para todo valor de $e$, o algoritmo $A_{e}$ é polinomial com os dados do problema e polinomial para $1 / e$.

Exemplo: O esquema de aproximação descrito em Sakarovitch (1984) para resolver o problema da mochila formulado abaixo é apresentado a seguir :

$$
K(b)=\left\{\begin{array}{c}
a_{1} x_{1}+\ldots+a_{n} x_{n} \leq b \\
c_{1} x_{1}+\ldots .+c_{n} x_{n}=z(\max )
\end{array} \quad x_{j} \in\{0,1\} j=1, \ldots, n\right.
$$

Sem perda de generalidade, pode-se supor:

$$
\begin{aligned}
& 0<a_{j} \leq b \quad j=1,2, \ldots, n \\
& c_{1} / a_{1} \geq c_{2} / a_{2} \geq \ldots . . c_{n} / a_{n}>0
\end{aligned}
$$

Designa-se por $\hat{\mathbf{x}}$ uma solução ótima de $K(\mathrm{~b})$ e por $\hat{\mathbf{z}}$ o valor da funçãoobjetivo correspondente $(\hat{z}=\mathrm{c} \hat{\mathbf{x}})$.

O esquema de aproximação comporta cinco fases:

1) Seja $\bar{x}^{k}$ um n-vetor definido por:

$$
\overline{\mathbf{x}}_{\mathrm{j}}^{\mathrm{k}}=\left\{\begin{array}{lll}
1 & \text { se } 1 \leq \mathrm{j} \leq \mathrm{k} \\
0 & \text { se } & \mathrm{k}<\mathrm{j}
\end{array}\right.
$$

e seja $\mathbf{k}(\mathrm{b})$ o valor máximo de $\mathrm{k}$ para o qual $\overline{\mathbf{x}}^{\mathrm{k}}$ é solução factível de $\mathrm{K}(\mathrm{b})$. Mostra-se facilmente, considerando-se $c^{\mathrm{k}(\mathrm{b})+1}<\hat{\mathrm{z}}$ que $\hat{\mathrm{z}} \leq \mathrm{c} \overline{\mathrm{x}}^{\mathrm{k}(\mathrm{b})+1} \leq 2 \hat{\mathrm{z}}$ 
2) Ao problema $\mathrm{K}(\mathrm{b})$, associa-se:

$$
\widetilde{K}(d)=\left\{\begin{array}{l}
a_{1} x_{1}+\ldots+a_{n} x_{n}=w(\min ) \\
c_{1} x_{1}+\ldots+c_{n} x_{n} \geq d
\end{array} \quad x_{j} \in\{0,1\} j=1, \ldots, n\right.
$$

Seja $\widetilde{\mathrm{x}}$ uma solução ótima de $\widetilde{\mathrm{K}}(\mathrm{d})$. Se $\widetilde{\mathrm{w}}(\mathrm{d})=\mathrm{a} \widetilde{\mathrm{x}} \leq \mathrm{b}<\widetilde{\mathrm{w}}(\mathrm{d}+1)$ então $\widetilde{\mathrm{x}}$ é uma solução ótima de $\mathrm{K}(\mathrm{b})$.

3) A $\varepsilon \geq 2 n / c \bar{x}^{k(b)+1}$, associa-se $\alpha=c \bar{x}^{k(b)+1} \varepsilon / 2 n$ e considera-se o problema aproximado $\mathrm{K}(\mathrm{b})$ :

$$
K^{\alpha}(b)\left\{\begin{array}{l}
a_{1} x_{1}+a_{2} x_{2}+\ldots+a_{n} x_{n} \leq b \\
c_{1}^{\alpha} x_{1}+c_{2}^{\alpha} x_{2}+\ldots+c_{n}^{\alpha} x_{n}=z^{\alpha}(\max )
\end{array} \quad x_{j} \in\{0,1\} \quad j=1,2, \ldots, n\right.
$$

com

$$
c_{j}^{\alpha}=\left[c_{j} / \alpha\right] \quad j=1,2, \ldots, n
$$

Seja $\hat{\mathrm{x}}^{\alpha}$ uma solução ótima de $\mathrm{K}^{\alpha}(\mathrm{b})$ e $\hat{\mathrm{z}}^{\alpha}=\mathrm{c}^{\alpha} \hat{\mathrm{x}}^{\alpha}$ o valor correspondente à função objetivo. Seguindo o raciocínio equivalente ao da fase 1 , obtém-se

$$
\hat{\mathrm{z}}^{\alpha} \leq \mathrm{c} \overline{\mathrm{x}}^{\mathrm{k}(\mathrm{b})+1}<2 \hat{\mathrm{z}}^{\alpha}
$$

Por outro lado:

$$
0 \leq \mathrm{c}_{\mathrm{j}}-\alpha \mathrm{c}_{\mathrm{j}}^{\alpha}<\alpha \quad \mathrm{j}=1,2, \ldots \mathrm{n}
$$

e, observando-se que $\hat{\mathbf{x}}^{\alpha}$ é solução factível de $\mathrm{K}(\mathrm{b})$ e $\hat{\mathrm{x}}$ é solução factível de $\mathrm{K}^{\alpha}(\mathrm{b})$ tem-se

$$
\alpha c^{\alpha} \hat{\mathrm{x}} \leq \alpha c^{\alpha} \hat{\mathbf{x}}^{\alpha} \leq c \hat{\mathrm{x}}^{\alpha} \leq \mathrm{c} \hat{\mathrm{x}} \leq \mathrm{c} \overline{\mathrm{x}}^{\mathrm{k}(\mathrm{b})+1}
$$

então:

$$
c \hat{\mathrm{x}}-\mathrm{c} \hat{\mathrm{X}}^{\alpha} \leq \mathrm{c} \hat{\mathrm{x}}-\alpha \mathrm{c}^{\alpha} \hat{\mathrm{x}}<\mathrm{n} \alpha
$$

Assim: 


$$
\left(\mathrm{c} \hat{\mathrm{X}}-\mathrm{c} \hat{\mathrm{X}}^{\alpha}\right) / \hat{\mathrm{z}}^{\alpha}<\mathrm{n} \alpha / \hat{\mathrm{z}}^{\alpha} \leq 2 \mathrm{n} \alpha / \mathrm{c} \overline{\mathrm{X}}^{\mathrm{k}(\mathrm{b})+1}=\varepsilon
$$

4) $\mathrm{A} \mathrm{K}^{\alpha}(\mathrm{b})$ associa-se, como em 2 :

$$
\widetilde{K}^{\alpha}(d)\left\{\begin{array}{l}
c_{1}^{\alpha} x_{1}+c_{2}^{\alpha} x_{2}+\ldots+c_{n}^{\alpha} x_{n} \geq d \\
a_{1} x_{1}+a_{2} x_{2}+\ldots+a_{n} x_{n}=w^{\alpha}(M i n)
\end{array} \quad x_{j} \in\{0,1\} \quad j=1,2, \ldots, n\right.
$$

Coloquemos $\overline{\mathrm{d}}=\mathrm{c}^{\mathrm{k}(\mathrm{b})+1} / \alpha$. Resultado de 2. e de 3., as soluções de $\widetilde{\mathrm{K}}^{\alpha}(\mathrm{d})$ para $\alpha=0,1, \ldots, \overline{\mathrm{d}}$ permitem a solução direta de uma solução ótima de $\mathrm{K}^{\alpha}(\mathrm{b})$, ou seja -resultado de 1- uma $\varepsilon$-aproximação para $\mathrm{K}(\mathrm{b})$. Para resolver $\widetilde{\mathrm{K}}^{\alpha}(\mathrm{d})$ para $d=0,1, \ldots, \bar{d}$, utiliza-se a equação de recorrência da Programação Dinâmica. Se $\widetilde{\mathrm{w}}_{\mathrm{k}}^{\alpha}(\delta)$ designa o valor da função objetivo o ótimo de

$$
\widetilde{\mathrm{K}}_{\mathrm{k}}^{\alpha}(\delta)\left\{\begin{array}{l}
\mathrm{c}_{1}^{\alpha} \mathrm{x}_{1}+\mathrm{c}_{2}^{\alpha} \mathrm{x}_{2}+\ldots+\mathrm{c}_{\mathrm{k}}^{\alpha} \mathrm{x}_{\mathrm{k}} \geq \delta \\
\mathrm{a}_{1} \mathrm{x}_{1}+\mathrm{a}_{2} \mathrm{x}_{2}+\ldots+\mathrm{a}_{\mathrm{k}} \mathrm{x}_{\mathrm{k}}=\mathrm{w}_{\mathrm{k}}^{\alpha}(\mathrm{Mim})
\end{array} \quad \mathrm{x}_{\mathrm{j}} \in\{0,1\} \quad \mathrm{j}=1,2, \ldots, \mathrm{k}\right.
$$

Tem-se:

$$
\widetilde{\mathrm{w}}_{\mathrm{k}}^{\alpha}(\delta)=\operatorname{Min}_{\mathrm{x}_{\mathrm{k}} \in\{0,1\}}\left[\widetilde{\mathrm{w}}_{\mathrm{k}-1}^{\alpha}(\delta) ; \widetilde{\mathrm{w}}_{\mathrm{k}-1}^{\alpha}\left(\delta-\mathrm{c}_{\mathrm{k}}^{\alpha}\right)+\mathrm{a}_{\mathrm{k}}\right]
$$

determina-se assim uma solução de $\widetilde{K}^{\alpha}(d)=\widetilde{K}_{n}^{\alpha}(d)$ em

$$
\mathrm{n}(\overline{\mathrm{d}}+1) \approx \mathrm{nc} \overline{\mathrm{x}}^{\mathrm{k}(\mathrm{b})+1} / \alpha=2 \mathrm{n}^{2} / \varepsilon
$$

operações. 
5) A restrição aparente $\varepsilon \geq \varepsilon_{0}=2 \mathrm{n} / \mathrm{c} \overline{\mathrm{x}}^{\mathrm{k}(\mathrm{b})+1}$ que parece à primeira vista uma má aproximação não se revela como tal de fato. Para $\varepsilon=\varepsilon_{0}$, tem-se com efeito $\alpha=1 \mathrm{e}$ $\mathrm{K}^{\alpha}(\mathrm{b})=\mathrm{K}(\mathrm{b})$. 


\section{CAPÍTULO 3}

\section{SEleção e CarRegamento de Máquinas:}

MOdelamento e ESTRATÉGia de RESOLUÇÃo

\subsection{Introdução}

Numerosos estudos tem sido realizados nos últimos anos com o objetivo de se resolver de maneira eficiente as versões específicas de modelamento propostas para 0 problema de seleção e carregamento de máquinas. Amini e Racer (1994), por exemplo, propõem o algoritmo aproximado VDSH (Variable - Depth Search Heuristic) para a resolução do "problema da mochila multidimensional" e fazem uma comparação de performance entre este e outros algoritmos aproximados descritos na literatura. A heurística VDSH é um método de busca local.

Ao contrário de Amini e Racer (1994), que resolvem globalmente um "problema da mochila multidimensional", Logendran et al. (1994) decompõem a resolução do problema de atribuição de peças a máquinas em duas fases: $\mathrm{Na} 1^{\underline{\underline{a}}}$ 
determina-se, para cada tipo de máquina, o número de máquinas efetivas necessárias à fabricação das peças e, para cada peça, um único roteiro de fabricação entre os diferentes roteiros disponíveis. $\mathrm{Na} 2^{\underline{a}}$ fase é realizada a atribuição. A busca proposta em Logendran et al. (1994) trata apenas a primeira fase da metodologia. A segunda fase não foi objeto de estudo.

Em Liao (1994), a seleção de um roteiro de fabricação para cada peça não é determinada por meio de uma heurística, como é feito por Logendran et al. (1994). Liao (1994) faz a formulação matemática do problema correspondente com o auxílio de variáveis inteiras, levando em consideração o volume de produção e a capacidade das máquinas. A resolução do modelo formulado é realizada pelo pacote computacional LINDO, que não permite, evidentemente, o tratamento de problemas de médio ou grande porte.

Sankaran e Kasilingam (1993) utilizam igualmente o pacote computacional LINDO associado a uma heurística para resolver o modelo de programação inteira proposto por eles para determinar simultaneamente as máquinas que executarão as operações sobre as peças e as células de fabricação para um sistema flexível de manufatura. Lashkari et al. (1987) utilizam o pacote computacional SAS/OR para resolver um modelo matemático em variáveis $0 / 1$ com o objetivo de atribuir produtos às máquinas. Este modelo contempla 0 custo de depreciação das máquinas e a disponibilidade limitada das mesmas. A utilização do pacote SAS/OR foi possível, pois as duas funções objetivo propostas no modelo foram linearizadas.

Outras formulações em variáveis inteiras são estudadas em Wilhelm e Shin (1985), Shtub (1988) e Nasr e Elsayed (1990). Wilhelm e Shin (1985) propõem um modelo para efetuar a escolha entre diferentes máquinas, daquela que executará uma determinada operação. A resolução do modelo é feita relaxando-se as restrições de integralidade e arredondando-se o resultado de modo a manter a factibilidade. Nasr e Elsayed (1990) propõem um modelo global para a atribuição de produtos a máquinas e sequenciamento da produção. $\mathrm{O}$ algoritmo de resolução proposto pelos autores faz uso da solução obtida para sucessivos problemas da designação (Gondran e Minoux, 1985). 
Sule (1991) trabalha com uma tabela, onde é fornecida a porcentagem de capacidade disponível em cada tipo de máquina que é consumida pelas diferentes peças a fabricar. $\mathrm{O}$ número de máquinas necessárias em cada tipo de máquina para a fabricação das peças que exigem o seu trabalho é igual à soma das porcentagens arredondada para o valor inteiro superior mais próximo da quantia obtida. Quando um número de máquinas calculado desta forma é capaz de fabricar globalmente as peças, mas não existe uma atribuição factível, avalia-se, por exemplo, o custo de se comprar uma nova máquina.

\subsection{Notação}

Dados os lotes de produtos a fabricar, os roteiros de fabricação dos lotes de produtos, as máquinas ferramenta disponíveis e as durações operatórias dos lotes de produtos sobre as máquinas, trata-se de $: 1$ ) escolher as máquinas para fabricar os lotes de produtos entre aquelas do parque disponível e 2) atribuir os lotes de produtos às máquinas escolhidas, respeitando-se as capacidades de fabricação das mesmas.

A notação abaixo será utilizada para apresentar a metodologia de resolução proposta. Assume-se que cada produto será fabricado em um único lote.

1) $\mathrm{nm} \_\mathrm{lt}=$ número de lotes de produtos a fabricar

2) $\mathrm{nm} \_\mathrm{pd}[\mathrm{i}]=$ número de produtos a fabricar no lote $\mathrm{i}$

3) per_tr = período de trabalho

4) nm_op[i] = número de operações executadas sobre o lote i

5) tipo[i, k= 1 a nm_op[i]] = tipo de máquina utilizada para execução da késima operação sobre o produto $\mathrm{i}$

6) nm_mq[j] = número de máquinas disponíveis no tipo de máquina j 
7) $r v[j, m=1$ a nm_mq[j]] = relação de velocidade da mésima máquina de tipo j. Observação: As máquinas de referência dentro de cada tipo têm rv[j, m] fixados iguais a 1.

8) duração[i, $k=1$ a nm_op[i]] = duração da késima operação executada sobre o produto $\mathrm{i}$, com relação à máquina de referência do tipo.

Observação: Uma duração igual a 1.2 sobre a máquina de referência corresponde a uma duração de 0.6 em uma máquina cuja relação de velocidade é igual a 2 .

\subsection{Determinação da matriz de cargas}

Para realizar a atribuição das máquinas, avalia-se em um primeiro tempo, a carga global de trabalho em relação a cada tipo de máquina. A partir dos roteiros de fabricação dos lotes de produtos, do número de produtos a fabricar em cada lote e das durações das operações, calcula-se a matriz de cargas de trabalho [lotes de produtos $\mathbf{x}$ tipos de máquinas].

Esta matriz traduz a carga de trabalho demandada por cada lote de produtos sobre cada tipo de máquina. Os elementos desta matriz são dados por :

$$
\operatorname{carga}[\mathrm{i}, \mathrm{j}]=\mathrm{nm} \_\mathrm{pd}[\mathrm{i}] \quad \sum_{\mathrm{k} / \mathrm{tipo}[\mathrm{i}, \mathrm{k}]=\mathrm{j}} \operatorname{duração}[\mathrm{i}, \mathrm{k}]
$$

Um lote de produtos cujo roteiro de fabricação utiliza o trabalho de um mesmo tipo de máquina mais de uma vez tem sua carga de trabalho sobre o tipo de máquina em questão igual a soma das durações destas operações multiplicada pelo número de 
produtos a fabricar nos respectivos lotes. Isto significa que estas operações são concentradas, em um primeiro tratamento, em um pacote como uma operação única e então atribuídas para execução em uma mesma máquina. Em um segundo tratamento, estas operações podem retomar suas individualidades e serem eventualmente executadas em máquinas diferentes, na medida em que os tipos e as máquinas disponíveis em cada tipo são conhecidos. Esta possibilidade deve ser considerada se, por exemplo, uma diminuição do tempo total de fabricação puder ser obtida através da execução de uma das operações em uma outra máquina disponível do mesmo tipo (Ferreira Ribeiro e Pradin, 1991a, b, c; Noronha e Ferreira Ribeiro, 1994).

\subsection{Formulação do Problema}

Cada coluna da matriz [lotes de produtos $\mathrm{x}$ tipos de máquinas], ou seja, cada tipo de máquina $\mathfrak{j}$, gera um problema específico a resolver : Dadas as máquinas disponíveis no tipo em questão, trata-se de encontrar uma combinação de máquinas capaz de efetuar as operações sobre os lotes que exigem sua intervenção e atribuir estas operações às máquinas desta combinação.

O programa matemático em variáveis $0 / 1$ (PM01j) dado abaixo, permite a resolução do problema proposto. Neste modelo, a variável bivalente xim designa a atribuição $\left(\mathrm{xim}_{\mathrm{i}}=1\right)$ ou a não atribuição $\left(\mathrm{xim}_{\mathrm{i}}=0\right)$ do lote de produtos $\mathrm{i}$ à máquina $\mathrm{m}$ do tipo $\mathrm{j}$ em questão. A primeira restrição 3.1 assegura que cada máquina deve ser capaz de executar os lotes que lhe forem atribuídos. A segunda restrição 3.2 estabelece que as operações a realizar sobre os produtos são indivisíveis; ou seja, uma vez iniciadas não podem ser interrompidas. A função-objetivo minimiza o critério de otimização escolhido pelo operador (a, b, ou c).

PM01j 


$$
\begin{aligned}
& \operatorname{minimizar} \sum_{\mathrm{m}=1}^{\mathrm{nm} m \mathrm{mq}[\mathrm{j}]} \Phi\left(\sum_{\mathrm{i}=1}^{\mathrm{nm}-\mathrm{lt}} \mathrm{x}_{\mathrm{im}}\right) * \text { critério[j,m] } \\
& \text { sujeito a } \quad \sum_{i=1}^{n m \_l t} \operatorname{carga}[i, j] * x_{i m} \leq \operatorname{cap}[j, m] \quad(m=1 \text { a nm_mq[j]) }
\end{aligned}
$$

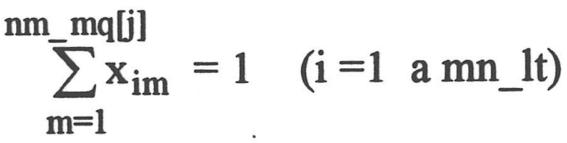

$$
\begin{aligned}
& \left.x_{\text {im }}=0 / 1 \text { (i=1 a nm_lt, m= } 1 \text { a nm_mq[j] }\right) \\
& \text { onde- } \Phi\left(\sum_{\mathrm{i}=1}^{\mathrm{nm} \mathrm{m}_{-} \mathrm{lt}} \mathrm{x}_{\mathrm{im}}\right)= \begin{cases}1 & \text { se } \sum_{\mathrm{i}=1}^{\mathrm{nm} \mathrm{m}_{\mathrm{im}} \mathrm{lt}}>0 \\
0 & \text { caso contrário }\end{cases} \\
& \text { - } \operatorname{cap}[\mathrm{j}, \mathrm{m}]=\operatorname{rv}[\mathrm{j}, \mathrm{m}] * \text { per_tr }=\text { capacidade de produção da máquina de tipo j } \\
& \text { - critério[j, m] = critério de otimização: }
\end{aligned}
$$

(a) número de máquinas;

(b) capacidade total das máquinas;

(c) custo de utilização das máquinas;

\subsection{Decomposição do Problema}

PM01j é NP-completo (Garey - Johnson, 1979) e o número de PM01j a resolver é igual ao número de tipos de máquinas utilizadas. 
Sejam: $\alpha$ o número de elementos carga[i, $j] \neq 0$ (j fixado, $i=1$ a nm_lt) e $\beta$ o número de máquinas de tipo $\mathrm{j}$. O número de restrições de PM01j é igual a $\alpha+\beta$ (desconsiderando-se $\mathrm{xim}=0 / 1)$ e o número de variáveis é igual a $\alpha * \beta$.

Se, para um certo tipo de máquina $\mathrm{j}$, dispõe-se de 5 máquinas para executar 30 lotes de produtos, PM01j apresentaria 35 restrições e 150 variáveis $0 / 1$ a calcular. A determinação de um número tão grande de variáveis exige um tempo de cálculo enorme. Os algoritmos de enumeração implícita (Balas, 1967), por exemplo, "permitem em geral a resolução de problemas apresentando em torno de 50 variáveis bivalentes; além deste limite o tempo de cálculo torna-se rapidamente proibitivo (...)" (Sakarovitch, 1984).

Propõe-se então a resolução de PM01j em duas etapas : Na primeira etapa, efetuamos uma escolha de máquinas para o tipo considerado, o que permite assegurar $\mathrm{o}$ atendimento da carga global de trabalho. Isto permite reduzir o número $\beta$ de máquinas a considerar e por conseguinte o número de variáveis $\alpha^{*} \beta$. Na segunda etapa, atribuí-se os lotes de produtos às máquinas, resolvendo-se o problema por enumeração implícita ou através de heurísticas.

\subsubsection{Escolha das Máquinas}

A escolha das máquinas responsáveis pela fabricação dos produtos é realizada separadamente para cada tipo de máquina $\mathrm{j}$ e independentemente do processo de atribuição dos lotes de produtos às máquinas. Uma vez escolhidas as máquinas, tem-se um problema de atribuição de dimensão menor ou igual à dimensão do problema a resolver considerando-se todas as máquinas inicialmente propostas.

A resolução do problema da mochila (MCHj) abaixo, permite a realização desta escolha. No modelo apresentado, a variável bivalente $\mathrm{y}_{\mathrm{m}}$ designa a escolha $\left(\mathrm{y}_{\mathrm{m}}=1\right)$ ou a não-escolha $\left(\mathrm{y}_{\mathrm{m}}=0\right)$ da máquina $\mathrm{m}$. A função-objetivo de $\mathrm{MCHj}$ minimiza o 
critério escolhido pelo operador (a, b ou c). A restrição principal 3.4 assegura que a capacidade das máquinas disponíveis é suficiente para realizar a carga de trabalho globalmente demandada pelos lotes de produtos.

$\mathrm{MCHj}$

$$
\begin{aligned}
& \operatorname{minimizar} \sum_{m=1}^{n m} \mathrm{mq}[j] \\
& \text { sujeito a } \quad \sum_{m=1}^{n m_{-} m q[j]} \operatorname{cap}[j, m] * y_{m} \geq \sum_{i=1}^{n m_{-} l t} \operatorname{carga}[i, j] \\
& y_{m}=0 / 1 \quad(m=1 \text { a nm_mq[j] })
\end{aligned}
$$

A diminuição do número de máquinas inicialmente propostas leva a uma diminuição do coeficiente $\beta$ e por conseguinte a uma diminuição do número de variáveis $\alpha_{*} \beta$ a determinar no problema de atribuição. Em nosso exemplo de 5 máquinas e 30 lotes, teríamos 5 variáveis 0/1 a determinar em $\mathrm{MCHj}$. Um método qualquer de Programação Inteira (mesmo a busca exaustiva) pode ser utilizado para obtenção da solução ótima deste problema.

Tal ótimo, entretanto, não é de muita utilidade, pois a existência de uma atribuição dos lotes às máquinas de uma combinação ótima não está evidentemente assegurada; somente está assegurado que as máquinas desta combinação são capazes de executar a carga global de trabalho sobre o tipo de máquina analisado.

Diante disto e da dimensão dos problemas a resolver, propomos a resolução de $\mathrm{MCHj}$ de duas diferentes maneiras:

$\left.1^{\mathbf{a}}\right)$ através da Programação Dinâmica, que permite a enumeração de várias soluções para o problema, inclusive da solução ótima; 
$2^{2}$ ) através de um procedimento heurístico composto de três etapas: 1) Geração de combinações de máquinas; 2) Submissão das combinações geradas à restrição principal de $\mathrm{MCHj}$; 3) Classificação de algumas combinações factíveis em uma lista segundo seu valor de função-objetivo.

Como resultado deste procedimento, obtém-se algumas ou todas as combinações de máquinas para as quais, na ordem do valor do critério a otimizar, é verificada a existência de uma atribuição factível dos lotes de produtos. $\mathrm{O}$ número de combinações estocadas no procedimento heurístico é um parâmetro definido pelo operador.

\subsubsection{Atribuição dos lotes de produtos às máquinas}

A resolução de $\mathrm{MCHj}$ na etapa precedente fornece as combinações de máquinas para as quais testa-se, nesta etapa, a existência de uma atribuição factível. Este teste é realizado primeiro para a combinação que apresenta o melhor valor de funçãoobjetivo; em seguida - se a atribuição não é possível - para o segundo valor de funçãoobjetivo, etc.

A simples resolução do sistema linear em variáveis bivalentes, formado pelas restrições de PM01j por enumeração implícita (ou heurísticas), é uma solução possível para o problema de atribuição. Uma outra alternativa consiste em definir um novo objetivo a atingir quando da resolução deste sistema, buscando-se assim uma atribuição otimizada dos lotes às máquinas e não uma atribuição qualquer. A funçãoobjetivo de PM01j após a resolução de $\mathrm{MCHj}$ não é mais otimizável pois é igual a constante. 
Como função-objetivo do novo problema de atribuição (PMM01j) com as restrições de PM01j, propõe-se:

$$
\operatorname{minimizar} \sum_{\mathrm{i}=1}^{\mathrm{nm}-\mathrm{lt}} \sum_{\mathrm{m}=1}^{\mathrm{nm}-\mathrm{mq}[\mathrm{j}]}[\mathrm{j}, \mathrm{m}] * \mathrm{x}_{\mathrm{im}}
$$

onde pen $[\mathrm{j}, \mathrm{m}]$ é a penalidade atribuída à utilização de cada máquina da combinação testada. Desta maneira, pode-se dirigir a atribuição dos lotes sobre certas máquinas (as mais rápidas ou as menos caras, etc.), à escolha do operador.

Em nosso método, caso o número de variáveis 0/1 de PMM01j a determinar seja inferior a 100, o problema é resolvido pelo algoritmo de enumeração implícita. Se o número de variáveis $0 / 1$ ultrapassar a centena, utiliza-se o algoritmo guloso. 


\section{Capítulo 4}

\section{ImplementaÇão do Algoritmo Proposto e TESTES REALIZADOS}

\section{1 - Introdução}

Neste capítulo é apresentada a implementação da estratégia de resolução do problema de seleção e carregamento de máquinas descrita no capítulo 3 e os resultados dos testes computacionais realizados. Nestes testes, fixou-se aleatoriamente como critério de otimização a minimização da capacidade total do parque de máquinas escolhidas para efetuar a fabricação. Como se trata de um dado fornecido pelo operador do programa, poderíamos ter igualmente escolhido como critério de 
otimização a minimização do número de máquinas da fábrica, ou um custo relativo às máquinas. A penalidade atribuída a cada uma das máquinas selecionadas foi fixada igual a 1 , de modo que não se procurou carregar a priori um conjunto arbitrário de máquinas. Desta forma, o programa efetuou o carregamento das máquinas sem o auxílio da lista de prioridade, distribuindo as operações a executar entre máquinas de mesma prioridade. $\mathrm{O}$ período de trabalho foi escolhido igual a 10 unidades de tempo para todos os exemplos testados.

O programa correspondente ao método de resolução proposto foi escrito em Turbo-Pascal 7.0.

\subsection{Algoritmo}

Os passos fundamentais do algoritmo implementado para efetuar a seleção e o carregamento das máquinas em um processo de fabricação estão resumidos no algoritmo $S \& C$ fornecido abaixo. Neste algoritmo está prevista a interferência do operador de modo a contemplar o conhecimento específico do mesmo sobre as particularidades do problema tratado em detrimento das técnicas matemáticas de otimização. No caso do operador do programa desejar promover alterações na seleção e carregamento de máquinas obtidos, o programa apenas verifica a factibilidade das modificações indicadas, ou seja, se a capacidade das máquinas não é excedida, e apresenta o resultado desta verificação ao mesmo. Em vista desta informação, o operador pode desistir da alteração desejada ou implementá-la mesmo no caso de capacidade de máquina insuficiente. 


\section{Algoritmo $S \& C$;}

Dados: critério de otimização;

penalidade das máquinas;

roteiros e tempos de fabricação dos lotes de produtos;

1) obtenção da matriz de cargas [lotes produtos $\mathrm{x}$ máquinas];

2) resolução do problema da mochila $\mathrm{MCH}$;

3) resolução do problema de atribuição PM01j;

4) apresentação do resultado obtido ao operador;

5) possibilidade de efetuar modificações sobre a solução apresentada;

\section{fim algoritmo $S \& C$;}

A matriz de cargas [produtos $\mathbf{x}$ máquinas] é obtida a partir dos roteiros de fabricação dos produtos, como exposto no item 3.3. O problema da atribuição PM01j e o problema da mochila $\mathrm{MCH}$ estão formulados nos itens 3.5.1 e 3.5.2 respectivamente. O problema de atribuição é gerado automaticamente pelo programa e resolvido pelo algoritmo de enumeração implícita apresentado no item 2.4.2, se o número de variáveis 0/1 a determinar for inferior a 100. Caso o número de variáveis ultrapasse a centena, utiliza-se o algoritmo guloso descrito no item 2.4.5.1. O problema da mochila $\mathrm{MCH}$ é igualmente gerado automaticamente pelo programa e pode ser resolvido pelos algoritmos seleção de máquinas 1 ou 2 , fornecidos abaixo. A utilização de um ou outro algoritmo para resolver $\mathrm{MCH}$ depende igualmente da dimensão do problema a resolver, e o critério estabelecido para tomar esta decisão é o mesmo empregado para a resolução de PM01j, ou seja: algoritmo seleção de máquinas 1 para mais de 100 variáveis e algoritmo seleção de máquinas 2 , caso contrário. $\mathrm{O}$ número de combinações classificadas e armazenadas em uma lista para posterior utilização durante a resolução de PM01j foi fixado arbitrariamente igual a 10 no algoritmo seleção de máquinas 1. 
Algoritmo Seleção de Máquinas 1 (máximo $=10$ soluções)

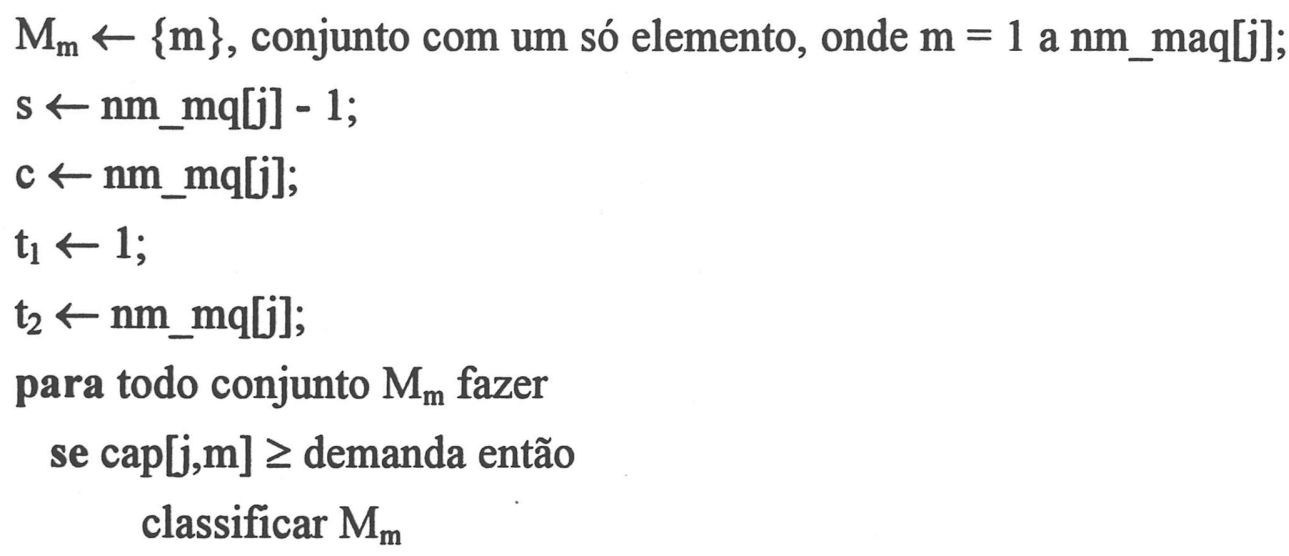

fim se

fim para

enquanto $s \neq 0$ fazer

$\mathrm{r} \leftarrow 0$;

para $e=t_{1}$ a $t_{2}$ fazer

para $\mathrm{k}=1$ a nm_mq[j] fazer

se $\mathbf{k} \in \mathrm{M}_{\mathrm{e}}$ então

$\mathrm{c} \leftarrow \mathrm{c}+1$

$\mathrm{M}_{\mathrm{c}} \leftarrow \mathrm{M}_{\mathrm{e}}+\{\mathrm{k}\}$;

se $M_{c} \neq M_{1}, \ldots, M_{c-1}$ então

$\mathrm{r} \leftarrow \mathrm{r}+1$;

se $\sum_{m \in M_{c}} \operatorname{cap}[j, m] \geq$ demanda então

classificar $\mathrm{M}_{\mathrm{c}}$;

fim se

senão $\mathrm{c} \leftarrow \mathrm{c}-1$;

fim se

fim se

fim para

fim para

$\mathrm{t}_{2} \leftarrow \mathrm{c}$;

$\mathrm{t}_{1} \leftarrow \mathrm{t}_{2}-\mathrm{r}+1$;

$s \leftarrow s+1$;

fim enquanto

fim algoritmo 
Algoritmo Seleção de Máquinas 2 (programação dinâmica)

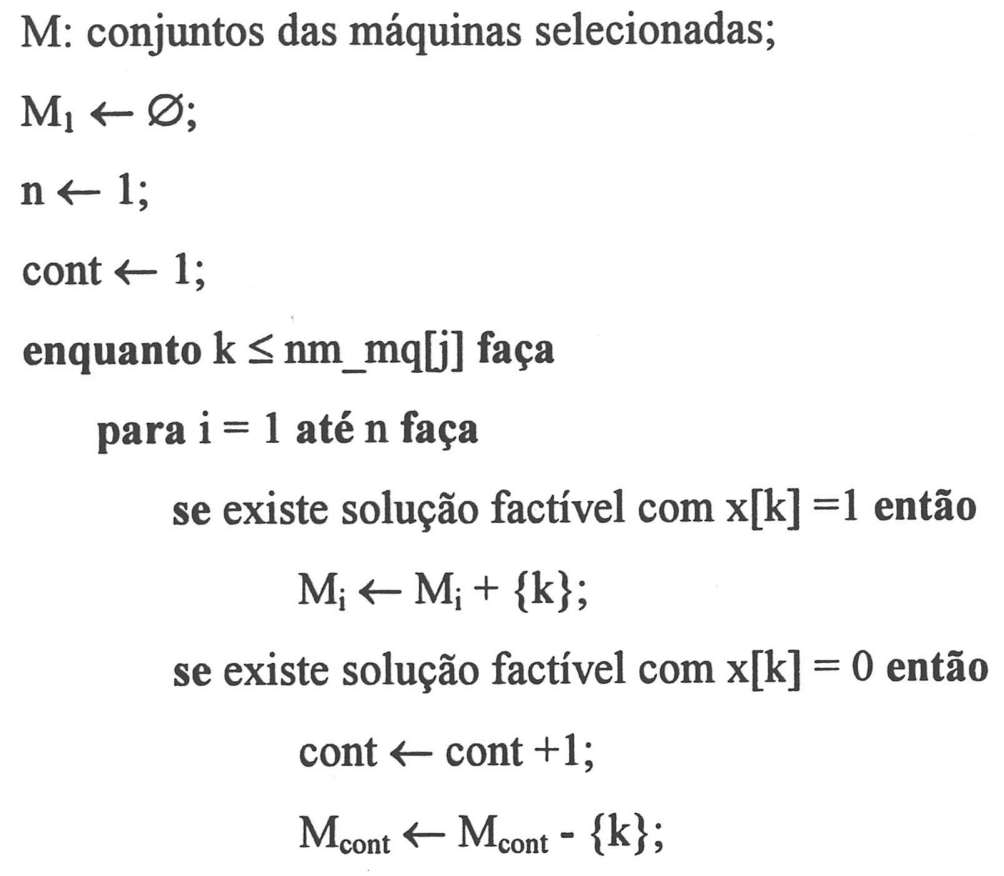

fim para;

$\mathrm{k} \leftarrow \mathbf{k}+1$

$\mathrm{n} \leftarrow$ cont;

fim enquanto;

fim algoritmo.

\subsection{Exemplo Ilustrativo}

As Tabelas 4.1 e 4.2 fornecem os dados do problema (Ferreira Ribeiro, 1992) que será resolvido para ilustrar o procedimento. A Tabela 4.3 fornece a matriz [produtos x tipos de máquinas] calculada.

Os resultados obtidos são apresentados na Tabela 4.4. As máquinas selecionadas para executar a fabricação foram as seguintes: uma máquina para o tipo de máquina 1, duas máquinas para o tipo 2, uma máquina para os tipos de máquina 3 , 4 e 5 , respectivamente. O tempo de cálculo exigido para resolver os 5 problemas de atribuição por enumeração implícita foi igual a 2 segundos (processador IBM-PC 386 $40 \mathrm{Mhz}$ ). $O$ período de trabalho foi fixado igual a 10 unidades de tempo. 


\begin{tabular}{|c|c|cccc|cccl|}
\hline Lote & nm_pd[i] & \multicolumn{3}{|c|}{ Roteiro } & \multicolumn{2}{|c|}{ Duração (unidade de tempo) } \\
\hline 1 & 1 & 2 & 4 & 5 & 2 & 2.0 & 2.5 & 1.0 & 0.5 \\
2 & 1 & 1 & 2 & 3 & 5 & 0.5 & 2.0 & 2.5 & 2.5 \\
3 & 1 & 4 & 5 & & 0.5 & 2.5 & & \\
4 & 1 & 2 & 5 & & 4.5 & 1.0 & & \\
5 & 1 & 1 & 3 & 5 & 5.0 & 3.5 & 1.0 & \\
6 & 1 & 2 & 3 & 4 & 1.5 & 0.5 & 0.5 & \\
7 & 1 & 1 & 2 & 3 & 5 & 1.5 & 2.5 & 0.5 & 2.0 \\
\hline
\end{tabular}

Tabela 4.1: Lotes, número de produtos por lote, roteiros, durações

\begin{tabular}{|c|c|c|c|c|}
\hline Tipo de & $\mathrm{nm} \_\mathrm{mq}[\mathrm{j}]$ & \multicolumn{3}{|c|}{ Relação de velocidade } \\
\hline 1 & 2 & 1.0 & 1.3 & \\
\hline 2 & 3 & 1.0 & 1.0 & 1.2 \\
\hline 3 & 3 & 1.0 & 1.2 & 1.5 \\
\hline 4 & 2 & 1.0 & 1.3 & \\
\hline 5 & 2 & 1.0 & 1.0 & \\
\hline
\end{tabular}

Tabela 4.2: Tipos, número de máquinas nos tipos, relações de velocidade

\begin{tabular}{|l|lllll|}
\cline { 2 - 6 } \multicolumn{1}{c|}{} & 1 & 2 & 3 & 4 & 5 \\
\hline 1 & 0.0 & 2.5 & 0.0 & 2.5 & 1.0 \\
2 & 0.5 & 2.0 & 2.5 & 0.0 & 2.5 \\
3 & 0.0 & 0.0 & 0.0 & 0.5 & 2.5 \\
4 & 0.0 & 4.5 & 0.0 & 0.0 & 1.0 \\
5 & 5.0 & 0.0 & 3.5 & 0.0 & 1.0 \\
6 & 0.0 & 1.5 & 0.5 & 0.5 & 0.0 \\
7 & 1.5 & 2.5 & 0.5 & 0.0 & 2.0 \\
\hline
\end{tabular}

Tabela 4.3: Matriz [lotes de produtos x tipos de máquinas] 


\begin{tabular}{|c|cccccc|}
\hline máquina $\rightarrow$ & 1 & 2 & 3 & 4 & 5 & 6 \\
\hline tipo $\rightarrow$ & 1 & 2 & 2 & 3 & 4 & 5 \\
\hline número $\rightarrow$ & 1 & 1 & 2 & 1 & 1 & 1 \\
\hline 1 & 0.0 & 2.5 & 0.0 & 0.0 & 2.5 & 1.0 \\
2 & 0.5 & 2.0 & 0.0 & 2.5 & 0.0 & 2.5 \\
3 & 0.0 & 0.0 & 0.0 & 0.0 & 0.5 & 2.5 \\
4 & 0.0 & 4.5 & 0.0 & 0.0 & 1.0 & 0.0 \\
5 & 5.0 & 0.0 & 0.0 & 3.5 & 0.0 & 1.0 \\
6 & 0.0 & 0.0 & 1.5 & 0.5 & 0.5 & 0.0 \\
7 & 0.5 & 0.0 & 2.5 & 0.5 & 0.0 & 2.0 \\
\hline Carga & 6.0 & 9.0 & 4.0 & 7.0 & 4.5 & 9.0 \\
\hline
\end{tabular}

Tabela 4.4: Matriz [lotes de produtos x máquinas]

\subsection{Interferência do Usuário}

O programa prevê a interferência do usuário sobre a solução obtida. No exemplo fornecido no item anterior, o usuário poderia solicitar a utilização da $3^{\underline{a}}$ máquina disponível no tipo de máquina 2, apesar desta máquina não ser necessária, uma vez que a soma das capacidades da $1^{\underline{a}}$ e da $2^{\underline{a}}$ máquinas é suficiente para fazer face à demanda. Da mesma forma o usuário poderia atribuir a execução da $1^{\mathrm{a}}$ operação sobre o produto 4 a esta máquina, modificando o carregamento proposto. A nova solução para o problema é fornecida na tabela 4.5. 


\begin{tabular}{|c|ccccccc|}
\hline máquina $\rightarrow$ & 1 & 2 & 3 & 4 & 5 & 6 & 7 \\
\hline tipo & 1 & 2 & 2 & 2 & 3 & 4 & 5 \\
\hline número $\rightarrow$ & 1 & 1 & 2 & 3 & 1 & 1 & 1 \\
\hline 1 & 0.0 & 2.5 & 0.0 & 0.0 & 0.0 & 2.5 & 1.0 \\
2 & 0.5 & 2.0 & 0.0 & 0.0 & 2.5 & 0.0 & 2.5 \\
3 & 0.0 & 0.0 & 0.0 & 0.0 & 0.0 & 0.5 & 2.5 \\
4 & 0.0 & 0.0 & 0.0 & 3.8 & 0.0 & 1.0 & 0.0 \\
5 & 5.0 & 0.0 & 0.0 & 0.0 & 3.5 & 0.0 & 1.0 \\
6 & 0.0 & 0.0 & 1.5 & 0.0 & 0.5 & 0.5 & 0.0 \\
7 & 0.5 & 0.0 & 2.5 & 0.0 & 0.5 & 0.0 & 2.0 \\
\hline
\end{tabular}

Tabela 4.5: Matriz [lotes de produtos x máquinas]

\subsection{Outros testes}

A Tabela 4.6, abaixo, exibe o resultado dos testes computacionais realizados (processador IBM-PC $386-40 \mathrm{MHz}$ ). Na primeira coluna desta tabela é fornecida a referência do problema escolhido:[CM-81], por exemplo, significa Chan e Milner, 1981; na segunda é dado o par (r,s), onde r é o número de produtos e s é o número de tipos de máquinas; na terceira e quarta colunas são fornecidos, respectivamente, o número de máquinas disponíveis para o planejamento e o número de operações a executar. Nas colunas seguintes, $\mathrm{T}_{\mathrm{SM} 1}$ é o tempo de cálculo em segundos que 0 programa despende para efetuar a escolha das máquinas com o algoritmo seleção de máquinas 1 e $\mathrm{T}_{\mathrm{SM} 2}$ com o algoritmo seleção de máquinas $2, \mathrm{~T}_{\mathrm{EI}}$ é o tempo de cálculo em segundos para o algoritmo de enumeração implícita e $\mathrm{T}_{\mathrm{GU}}$ para $\mathrm{o}$ algoritmo guloso. 
$\mathrm{Na}$ Tabela 4.6, - indica que o tempo computacional foi inferior a 0.1 segundo e $>$ indica um tempo superior a 30 minutos.

\begin{tabular}{|c|c|c|c|c|c|c|c|}
\hline Exemplos & $\begin{array}{c}\mathrm{n}^{\circ} \text { de produtos } \\
\text { e tipos de } \\
\text { máquinas }\end{array}$ & $\begin{array}{c}\mathrm{n}^{\circ} \text { de } \\
\text { máquinas } \\
\text { disponíveis }\end{array}$ & $\begin{array}{c}\mathrm{n}^{\circ} \text { de } \\
\text { operações }\end{array}$ & $\mathrm{T}_{\mathrm{SM} 1}$ & $\mathrm{~T}_{\mathrm{SM} 2}$ & $\mathrm{~T}_{\mathrm{EI}}$ & $\mathrm{T}_{\mathrm{GU}}$ \\
\hline$[\mathrm{FE}-92]$ & $7 \times 5$ & 12 & 21 & - & - & 2.0 & - \\
\hline$[\mathrm{ME}-88]$ & $9 \times 7$ & 14 & 45 & - & - & 22.4 & - \\
\hline$[\mathrm{ME}-88]$ & $9 \times 7$ & 21 & 45 & - & - & 154.9 & - \\
\hline$[\mathrm{CM}-81]$ & $10 \times 15$ & 15 & 46 & - & - & - & - \\
\hline$[\mathrm{SR}-90]$ & $20 \times 10$ & 10 & 49 & - & - & - & - \\
\hline$[\mathrm{HA}-90]$ & $20 \times 20$ & 20 & 79 & - & - & - & - \\
\hline$[\mathrm{GA}-85]$ & $30 \times 12$ & 24 & 131 & - & - & $>$ & - \\
\hline$[\mathrm{KV}-87]$ & $41 \times 30$ & 30 & 128 & - & - & - & - \\
\hline$[\mathrm{BU}-75]$ & $43 \times 16$ & 16 & 127 & - & - & - & - \\
\hline$[\mathrm{BU}-75]$ & $43 \times 16$ & 48 & 127 & - & - & $>$ & - \\
\hline
\end{tabular}

Tabela 4.6. Exemplos e tempos de cálculo (em segundos)

\subsection{Comentários}

$\mathrm{O}$ procedimento de resolução em duas fases do programa matemático em variáveis bivalentes PM01j (busca de soluções factíveis para $\mathrm{MCH}$ através do algoritmo seleção de máquina seguida de enumeração implícita ou algoritmo "guloso") explora as particularidades do problema tratado (escolha de máquinas, atribuição dos lotes de produtos as máquinas) para obter solução ótima ou realizável em tempo de cálculo aceitável (alguns segundos) sobre micro- computador 
(processador IBM-PC 386 - $40 \mathrm{MHz}$ ), mesmo no caso de problemas de razoável dimensão.

A Tabela 4.6 apresenta a resolução de 10 exemplos extraídos da literatura. Os resultados obtidos foram os mesmos pelos 4 algoritmos disponíveis. O tempo computacional exigido pelo algoritmo de enumeração implícita é o mais elevado, conforme esperado. Deve-se observar na tabela 4.6 que quando o número de máquinas disponíveis para o planejamento é igual ao número de tipos de máquinas, o tempo de cálculo do algoritmo de enumeração implícita é irrelevante, isto porque o programa dispõe de uma heurística para a verificação da existência de atribuição factível, quando existe apenas uma máquina disponível no tipo. Caso a heurística encontre uma resposta afirmativa, a atribuição encontrada é confirmada como solução.

A programação dinâmica (algoritmo seleção de máquina 2) mostrou-se tão rápida quanto a enumeração de 10 soluções factíveis (algoritmo seleção de máquina 1). O inconveniente desta técnica, todavia, encontra-se na ocupação de memória, uma vez que é necessário armazenar as diferentes soluções ótimas em cada estágios para efetuar-se a recuperação da trajetória na etapa subsequente. Isto limita a sua utilização para resolução de problemas de grande porte.

O programa correspondente ao método proposto foi escrito em linguagem Turbo-Pascal e implantado em micro computador. Ele gera automaticamente os programas matemáticos a resolver e apresenta ao operador a atribuição obtida. $\mathrm{O}$ operador pode introduzir novas máquinas na solução apresentada e modificar o carregamento proposto. Tendo em vista a facilidade com que esta ferramenta de cálculo gera alternativas de decisão dadas as duas variantes algorítmicas para os dois problemas estudados e sua proximidade com a realidade industrial (máquinas de velocidades variável, durações operatórias variáveis, capacidade das máquinas, etc.) pode- se imaginar sua utilização em tempo real. 


\section{Capítulo 5}

\section{CONCLUSÃO}

A seleção de máquinas para executar as operações sobres os lotes de produtos e o carregamento destas operações nas máquinas da combinação escolhida é tarefa de fundamental importância dentro da metodologia de planejamento da operação de sistemas produtivos na qual este estudo está inserido, a saber:

fase 1: seleção e carregamento de máquinas;

fase 2: projeto de células de manufatura;

fase 3: sequenciamento de operações.

O projeto de células de manufatura e o sequenciamento da produção são fases que sucedem a seleção e o carregamento de máquinas, de modo que a qualidade das soluções obtidas nestas etapas dependem fortemente das decisões tomadas na primeira fase. 
Nesta dissertação é proposto um modelo para o problema de seleção e carregamento de máquinas e uma estratégia de resolução do mesmo. A preocupação em estudar uma formulação matemática e elaborar um tratamento específico para a mesma, derivam (I) da necessidade de se obter a solução ótima ou uma solução $\varepsilon$ ótima tendo em vista o emprego do programa computacional correspondente na resolução de problemas reais e (II) da forte complexidade dos problemas em questão, dado o caráter NP-completo dos mesmos. A formulação matemática faz uso de variáveis bivalentes $0 / 1$ e os métodos de resolução propostos na literatura para 0 tratamento deste tipo de problema não garantem, em geral a obtenção de uma solução de boa qualidade em um tempo computacional razoável.

A estratégia de resolução adotada para o problema faz uso de características específicas do mesmo que permitem decomposição e hierarquização: $1^{\underline{0}}$ ) seleção das máquinas; $2^{\underline{0}}$ ) carregamento. Além disto, optou-se pelo emprego de heurísticas para 0 tratamento de problemas de grande porte, reservando-se os algoritmo exatos para a resolução dos problemas de pequeno porte, onde o tempo computacional requerido não ultrapasse 60 segundos. Desta forma, dispõe-se de um programa computacional extremamente rápido, capaz de operar em tempo real, selecionar e carregar novas máquinas em caso de pane de uma máquina, refugos, novas encomendas, etc.

A abordagem proposta nesta dissertação para a resolução do problema de seleção e carregamento de máquinas leva em consideração vários parâmetros importantes como a capacidade das máquinas, durações operatórias variáveis, etc., o que a torna bastante próxima da realidade industrial. O modelo adotado para caracterizar as máquinas foi a relação de velocidade, na linha de trabalho definida por Garcia et al. (1975), Meguelati (1988), Ferreira Ribeiro (1991). Um outro modelo (por exemplo: durações diferentes para cada operação segundo a máquina utilizada para executá-la) pode, entretanto ser introduzido na abordagem proposta sem nenhum inconveniente.

Os métodos de resolução desenvolvidos para programação inteira estudados nestas dissertação foram os seguintes: 1) separação e avaliação, 2) enumeração implícita, 3) planos de corte, 4) programação dinâmica e 5) algoritmos aproximados. $O$ 
algoritmo de enumeração implícita é utilizado no programa computacional desenvolvido para resolver o problema de atribuição das operações às máquinas, se o número de variável $0 / 1$ a determinar não ultrapassar a centena e, caso contrário, utiliza-se o algoritmo guloso. Um processo de enumeração de soluções factíveis para 0 modelo da mochila é ativado com o objetivo de gerar combinações de máquinas capazes de executar o conjunto global de operações na fábrica. Este processo é realizado via programação dinâmica, se o número de variáveis a determinar for inferior a uma centena, ou via enumeração simples de um conjunto de soluções de cardinal (inferior ou) igual a 10 , caso contrário.

O estudo de diferentes técnicas para a resolução dos problemas de programação inteira, o modelamento específico realizado para o problema de seleção $\mathrm{e}$ carregamento de máquinas, assim como a proposição de um novo método para a resolução do mesmo, permitiram a redação de três artigos, dois destes publicados em congressos nacionais e outro submetido a uma revista nacional (Medeiros e Ferreira Ribeiro, 1995a, b; Medeiros et al., 1995). Entre as propostas de continuidade deste trabalho, podemos destacar:

1) realização de um estudo bibliográfico mais profundo, consultando-se outras áreas de conhecimento, tais como sistemas especialistas, algoritmos genéticos e conjuntos nebulosos;

2) implementação do programa computacional desenvolvido em paralelo, uma vez que para cada coluna $\mathrm{j}$ da matriz [lotes de produtos $\mathrm{x}$ tipos de máquinas] é resolvido um problema de otimização totalmente independente um do outro;

3) realização de testes com o programa computacional disponível para problemas de grande porte, com dados reais ou gerados aleatoriamente, com o objetivo de estudar a performance do mesmo e levantar os pontos suscetíveis de reestudo e otimização;

4) introdução de técnicas especiais no algoritmo de programação dinâmica utilizado para resolver $\mathrm{MCH}$, tais como a PDAS (programação dinâmica por aproximação sucessivas) ou a PDDD (programação dinâmica discreta diferencial), com 
o objetivo de economizar memória da máquina e poder resolver problemas de maior dimensão (Wagner, 1986);

5) introdução de aperfeiçoamentos no método de enumeração implícita utilizado para resolver PMM01j, tais como a realização de testes suplementares (Sakarovitch, 1984) ou a adoção das restrições "surrogates" (Salkin, 1975), de modo a utilizar-se o algoritmo guloso com menor frequência e resolver-se de maneira ótima e em tempo de cálculo aceitável problemas reais de grande porte. 


\section{REFERÊNCIAS BIBLIOGRÁFICAS}

AHO, A., HOPCROFT, J. ULLMAN, J., Data Structures and Algorithms, Addison Wesley, 1983

AMINI, M. M., RACER, M., (1994), A Rigorous Computacional Comparison of Alternative Solution Methods for the Generalized Assignment Problem, Management Science, 40,7 , pp. 341-348

ARDUINO, A., (1972), Programação Dinâmica, COPPE - UFRJ

BALAS, E., Discrete Programming by the Filter Method, Operations Research, 15, pp. 915-957, 1967

BALLAKUR, A., STEUDEL, H. J., (1987), A Within-Cell Based Heuristic for Designing CMS, International Journal of Production Research, 25, 5, pp. 639-665

BARBOSA, S., M., FERREIRA RIBEIRO, J., F., (1995) Projeto de Células de Manufaturas com Número Mínimo de Movimento Inter-Células, CNMAC '95, Curitiba, PR, pp. 430-434

BRONSON, R., (1985), Pesquisa Operacional, Mc Graw-Hill 
BURBIDGE, J. L., (1975), The Introduction of Group Technology, John Wiley

CAMPELlO, R. E., MACULAN, N., (1994), Algoritmos e Heurísticas Desenvolvimento e Avaliação de Performance, Eduff

CHAN, H. M., MILNER, D. A., (1981), Direct Clustering Algorithm for Group Formation in Cellular Manufacture, Journal of Manufacturing Systems, 1, pp. 399-416

COOK, (1971), The Complexity of Theorem Proving Procedures, $3^{\text {rd }}$ ACM Symposium on Theory of Computing, pp. 151-158

FERREIRA RIBEIRO, J. F. (1991), Constitution d'Ilots et Ordonnancement dans un Atelier de Production, Tese de Doutorado LAAS/INSA, Toulouse, França

FERREIRA RIBEIRO, J. F., PRADIN, B., (1991a), TEGO : Un Logiciel pour l'Organisation en Ilots et l'Ordonnancement d'Ateliers de Production, $3^{\text {ème }}$ Congrès International de Génie Industriel, Tours, França, pp. 888-896

FERREIRA RIBEIRO, J. F., PRADIN, B., (1991b), Selection of Manufacturing Cells for Group Technology, IMACS Symposium on Modelling and Control of Technological Systems, Lille, França, pp. 675-681

FERREIRA RIBEIRO, J. F., PRADIN, B., (1991c), Affectation de Machines et Constitution d'Ilots en Technologie de Groupe, European Control Conference, Grenoble, França, pp. 2128-2133

FERREIRA RIBEIRO, J. F., (1992), Escolha e Atribuição de Máquinas, XII ENEGEP, São Paulo, Brasil, p. 37-43

FERREIRA RIBEIRO, J. F., PRADIN, B. (1993), A Methodology for Cellular Manufacturing Design, International Journal of Production Research, 31, 1, pp. 235250

FERREIRA RIBEIRO, J. F., RIBEIRO, C. M., PRADIN, B., (1993), Un Algorithme Basé sur les Ilots de Fabrication pour l'Ordonnancement, IV Congrès International de Génie des Systèmes Industriels, Marseille, França, pp. 219-224 
FERREIRA RIBEIRO, J. F., RIBEIRO, C. M., (1993), "An Algorithm for Obtaining Manufacturing Cells", (1993), IFAC'93 - XIII World Congress International Federation of Automatic Control, Sydney, Austrália, pp. 327-330

GARCIA, H., MUTEL, B., PROTH, J., M., (1985), Familes de Produits et Ilots de Fabrication: Le Cas de Machines Multiples, Rapport INRIA 469, França

GAREY, M. R., JOHNSON, D. S., (1979), Computers and Intractability : A Guide to the Theory of NP-Completeness, Freeman

GONDRAN, M., MINOUX, M., (1985), Graphes et Algorithmes, Eyrolles

HARHALAKIS, G., NAGI, R., PROTH, J. M., (1990), An Efficient Heuristic in Manufacturing Cell Formation for GT Applications, International Journal of Production Research, 28, 1, pp. 185-198

KUMAR, K. R., VANELLI, A., (1987), Strategic Subcontracting for Efficient Disaggregated Manufacturing, International Journal of Production Research, 25, 12, pp. $1715-1728$

LARSON, E., R., (1968), State Increment Dynamic Programming, American Elsevier Publishing Company

LASHKARI, R. S., DUTTA, S. P., PADHYE, A. M., (1987), A New Formulation of Operation Allocation Problem in FMS - Mathematical Modelling and Computacional Experience, International Journal of Production Research, 25, 9, pp. 1267-1283

LIAO, T. W., (1994), Design of Line-Type Cellular Manufacturing Systems for Minimum Operating and Material Handling Costs, International Journal of Production Research, 32, 2, pp. 387-397

LOGENDRAN, R., RAMAKRISHNA, P., SRIKANDARAJ, C., (1994), Tabu-SearchBased Heuristics for Cellular Manufacturing Systems in the Presence of Alternative Process Plans, International Journal of Production Research, 32, 2, pp. 273-297 
MEDEIROS, C. A., FERREIRA RIBEIRO, J. F., (1995), Um Método para o Carregamento de Máquinas, XVIII CNMAC, Curitiba, PR, pp. 688-692

MEDEIROS, C. A., FERREIRA RIBEIRO, J. F., (1995), Otimização da Carga de Máquinas, XV ENEGEP, São Carlos, SP, pp. 1241-1245

MEDEIROS, C. A., FERREIRA RIBEIRO, J. F., RIBEIRO, C. M., OLIVEIRA, M. M. B., (1995), Seleção e Carregamento de Máquinas, Revista Brasileira de Ciências Mecânicas (submetido)

MEGUELATI, S., (1988), Méthodes de Classification pour la Constitution d'Ilots de Fabrication et l'Ordonnancement, Tese de Doutorado INSA/LAAS, Toulouse, França

MINOUX, M., (1988), Programmation Mathématique - Théorie et Algorithmes (vols. 1 e 2), Dunod

NASR, N., ELSAYED, E. A., (1990), Job Shop Scheduling with Alternative Machines, International Journal of Production Research, 28, 9, pp. 1595-1609

NORONHA, A. B., FERREIRA RIBEIRO, J. F., (1994), Um Método para o Sequenciamento de Operações Baseado em Busca Arborescente e Proposições, XV CILAMCE, Belo Horizonte, MG, pp. 1452-1459

OLIVEIRA, M. M. B., FERREIRA RIBEIRO, J. F., RIBEIRO, C. M., (1994), Sequenciamento de Operações Baseado na Decomposição dos Sistemas de Manufatura e Uso de Processamento Paralelo, X CBA / VI CLACA, Rio de Janeiro, RJ, pp. 133138

ORLICKY, J., (1965), Material Requirements Planning, Librairie Lavoisier

PAPADIMITRIOU, C. H., STEIGLITZ, K., (1982), Combinatorial Optimization: Algorithms and Complexity, Prentice Hall

SAKAROVITCH, M., (1984), Optimisation Combinatoire : Programmation Discrète, Hermann 
SALKIN, H. M., (1975), Integer Programming, Addison Wesley

SANKARAN, S., KASILINGAM, R. G., (1993), One Cell Size and Machine Requirements Planning in GT Systems, European Journal of Operations Research, 69, 3, pp. 373-383

SCHONBERGER, R. J., (1982), Management by japanese systems, Praeger Publishers SHTUB, A., (1989), Modelling GT Cell Formation as a Generalized Assignment Problem, International Journal of Production Research 27, 5, pp. 775-782

SRINIVASAN, G., NARENDAN, T. T., MAHAVEDAN, B., (1990), An Assignment Model for the Part-Families Problem in GT, International Journal of Production Research, 28, 1, pp. 145-152

SULE, D. R., (1991), Machine Capacity Planning in GT, International Journal of Production Research, 29, 9, pp. 1909-1922

SZWARCFITER, J. L., (1983), Grafos e Algoritmos Computacionais, Campus

WAGNER, H., M., (1986), Pesquisa Operacional, Prentice / Hall do Brasil

WILHELM, W. E., SHIN, H. M., (1985), Effectiveness of Alternate Operations in a FMS, International Journal of Production Research, 23, 1, pp. 65-79 